\title{
Simulation and evaluation of utilization pathways of biomasses based on thermodynamic data prediction
}

Qian, Hongliang; Chen, Wei; Zhu, Weiwei; Liu, Chang; Lu, Xiaohua; Guo, Xiaojing; Huang, Dechun; Liang, Xiaodong; Kontogeorgis, Georgios M.

\section{Published in:}

Energy

Link to article, DOI:

10.1016/j.energy.2019.01.152

Publication date:

2019

Document Version

Peer reviewed version

Link back to DTU Orbit

Citation (APA):

Qian, H., Chen, W., Zhu, W., Liu, C., Lu, X., Guo, X., Huang, D., Liang, X., \& Kontogeorgis, G. M. (2019). Simulation and evaluation of utilization pathways of biomasses based on thermodynamic data prediction. Energy, 173, 610-625. https://doi.org/10.1016/j.energy.2019.01.152

\section{General rights}

Copyright and moral rights for the publications made accessible in the public portal are retained by the authors and/or other copyright owners and it is a condition of accessing publications that users recognise and abide by the legal requirements associated with these rights.

- Users may download and print one copy of any publication from the public portal for the purpose of private study or research.

- You may not further distribute the material or use it for any profit-making activity or commercial gain

- You may freely distribute the URL identifying the publication in the public portal 


\section{Accepted Manuscript}

Simulation and evaluation of utilization pathways of biomasses based on thermodynamic data prediction

Hongliang Qian, Wei Chen, Weiwei Zhu, Chang Liu, Xiaohua Lu, Xiaojing Guo,

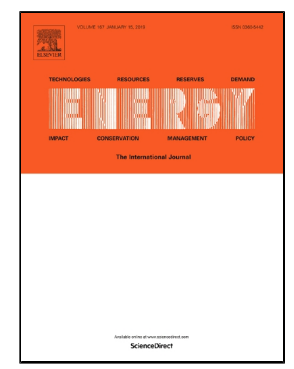

Dechun Huang, Xiaodong Liang, Georgios M. Kontogeorgis

PII:

S0360-5442(19)30168-9

DOI:

10.1016/j.energy.2019.01.152

Reference:

EGY 14625

To appear in:

Energy

Received Date:

10 June 2018

Accepted Date:

29 January 2019

Please cite this article as: Hongliang Qian, Wei Chen, Weiwei Zhu, Chang Liu, Xiaohua Lu, Xiaojing Guo, Dechun Huang, Xiaodong Liang, Georgios M. Kontogeorgis, Simulation and evaluation of utilization pathways of biomasses based on thermodynamic data prediction, Energy (2019), doi: 10.1016/j.energy.2019.01.152

This is a PDF file of an unedited manuscript that has been accepted for publication. As a service to our customers we are providing this early version of the manuscript. The manuscript will undergo copyediting, typesetting, and review of the resulting proof before it is published in its final form. Please note that during the production process errors may be discovered which could affect the content, and all legal disclaimers that apply to the journal pertain. 


\title{
Simulation and evaluation of utilization pathways of biomasses based on thermodynamic data prediction
}

Hongliang Qian ${ }^{\mathrm{a}, \mathrm{d}, 1}$, Wei Chen ${ }^{\mathrm{a}, 1}$, Weiwei Zhu ${ }^{\mathrm{a}}$, Chang Liu ${ }^{\mathrm{b}}$, Xiaohua Lu ${ }^{\mathrm{b}}$, Xiaojing Guo ${ }^{\mathrm{c}}$, Dechun

Huang $^{a^{*}}$, Xiaodong Liang ${ }^{\mathrm{d}}$, Georgios M. Kontogeorgis ${ }^{\mathrm{d}}$

a Department of Pharmaceutical Engineering, China Pharmaceutical University, Nanjing 210009, China

${ }^{\mathrm{b}}$ State Key Laboratory of Materials-Oriented Chemical Engineering, Nanjing Tech University, Nanjing 210009, China

c The Education Ministry Key Laboratory of Resource Chemistry, Shanghai Key Laboratory of Rare Earth Functional Materials and Department of Chemistry and Chemical Engineering, Shanghai Normal University, Shanghai 200234, China

${ }^{d}$ Department of Chemical and Biochemical Engineering, Technical University of Denmark, DK-2800 Kgs. Lyngby, Denmark

\begin{abstract}
It is important to evaluate the utilization pathways of biomasses as there are different multiple choices for various types of biomasses. A method using the functional exergy efficiency as a unified protocol is proposed to evaluate the effectiveness of energy utilization in three utilization pathways of biomasses: pyrolysis, oxygen gasification and anaerobic digestion. The results show that straws are more suitable than manures used in the pyrolysis process. Functional exergy efficiencies of the oxygen gasification process of six biomasses are all higher than those of the pyrolysis process. The functional exergy efficiencies of the manures have increased, becoming close to those of straws. For the anaerobic digestion process, the functional exergy efficiencies of straws are generally lower than that of manures. Manures with low lignin content (chicken manure in this study) are more suitable as the feedstock of anaerobic digestion process. The functional exergy efficiencies of anaerobic digestion are lower than those of the pyrolysis and gasification processes while the temperature exceeds $850{ }^{\circ} \mathrm{C}$.
\end{abstract}

Keywords: Biomass utilization, Gibbs energy minimization, PBMP model, Process evaluation, Functional exergy efficiency

\section{Introduction}

Alterations to the climate due to temperature rise caused by the greenhouse effect pose a risk to humanity, and other species. Greenhouse gas emissions from anthropogenic activities such as the

\footnotetext{
${ }^{1}$ These authors contributed equally to this work and should be considered co-first authors

*Corresponding Author

Tel.: +86 21 39194366. E-mail: guoxj@shnu.edu.cn (X. J. Guo).

Tel.: +86 25 83244816. E-mail: cpuhdc@cpu.edu.cn (D. C. Huang).
} 
burning of fossil fuels for power generation are major contributors to the climate change. This necessitates a switch from conventional to renewable power sources, e.g. solar photovoltaic, wind, biomass and hydroelectric generation [1], among which biomass is one of the most important energy sources in near future [2]. Biomass energy is a $\mathrm{CO}_{2}$-zero energy that does not interfere with the global carbon itself [3]. If the biomass is not used effectively, however, it will cause serious environmental pollution [4]. Therefore, the utilization of biomass has triple advantage of energy conservation, emission reduction and resource utilization.

Biomass resources include wood and wood wastes, agricultural crops and their waste byproducts, municipal solid waste, animal wastes, waste from food processing and aquatic plants and algae [5]. From the proximate analysis or ultimate analysis of biomass, the composition of biomasses varies depending on the types of biomasses considered and even for the same types of biomasses they may vary at different regions and seasons. The chemical conversion technologies for utilizing biomass can be divided into three basic categories: direct combustion processes, thermochemical processes (pyrolysis process, gasification process and direct liquefaction), biochemical processes (anaerobic digestion and alcoholic fermentation). Different utilization pathways and various types of biomasses lead to issues such as the lack of unified protocol to evaluate the biomass utilization. For example, is one type of corn stovers suitable for pyrolysis utilization, or gasification utilization, or anaerobic digestion utilization? In this study, we focus on how to evaluate the utilization pathways of biomasses with respect to energy utilization. The method is, thus, to simulate different utilization pathways and then to evaluate the effective utilization of energy based on the simulation results.

The thermochemical conversion process can be simulated by kinetic mathematical models [6], artificial neural networks models [7], and equilibrium models [8]. The Gibbs energy minimization method is one of the equilibrium models, and it does not involve specific chemical reaction equations and has a high degree of thermodynamic consistency [9]. High accuracy of thermodynamic data is a prerequisite of process simulation results obtained from the Gibbs energy minimization method. The biochemical conversion processes are simulated by rate-limitation step models [10], anaerobic digestion No.1 [11], artificial neural networks models [12], and practical biochemical methane potential (PBMP) model [13] in the literature. In this study, the PBMP model is selected for the process of methane production evaluation to assess the performance of an anaerobic digester. 
In the field of power plants, exergy efficiency is used to evaluate the effective utilization of energy and can be divided into two different approaches (a brute-force or functional exergy efficiency). A brute-force exergy efficiency for any system is defined as the ratio of the sum of all output exergy terms to the sum of all input exergy terms. Compared with the brute-force exergy efficiency, a functional exergy efficiency for any system is defined as the ratio of the exergy associated with the desired energy output to the exergy associated with the energy expended to achieve the desired output [14]. For thermochemical processes, the main criteria of the effective utilization of energy are the loss of exergy $\left(\mathrm{Ex}_{\text {loss }}\right)$ and brute-force exergy efficiency $[15,16]$. However, for the biochemical utilization of biomasses in order to obtain biogas, any exergy analysis is basically not considered because of the difficulty to determine the exergy of fermentation broth, biogas slurry and biogas residue. Therefore, output to input ratio of energy efficiency is selected as an effective indicator of energy utilization [17]. Since the energy efficiency is based on the first law of thermodynamics, so it cannot truly reflect the utilization of energy. As we all know, the main tasks of thermochemical conversion and anaerobic digestion of biomass are to produce syngas and biogas, respectively. Therefore, the functional exergy efficiency (desired outputs are syngas and biogas, respectively) instead of the brute-force exergy efficiency is extended to evaluate the utilization pathways of biomasses in this study.

The main objective of this study is to compare different utilization pathways of various biomasses. It is necessary to predict thermodynamic data of biomasses as their types and compositions vary. Based on thermodynamic data prediction, the pyrolysis and oxygen gasification processes of biomasses are simulated by the Gibbs energy minimization method. Biogas data of anaerobic digestion process are obtained through the PBMP model. The functional exergy efficiencies of utilization pathways of biomasses are evaluated based on the process simulation results. The innovative aspects of this study are related to the following two points: (1) The functional exergy efficiency concept was extended to evaluate utilization pathways of biomasses; (2) Process simulation and energy evaluation are based on the thermodynamic data predicted by the high accurate models of higher heat value $(H H V)[18]$ and chemical exergy [19] of dry biomass. In summary, only with the help of the composition of biomasses, utilization pathways of biomasses can be simulated and evaluated based on thermodynamic data prediction.

\section{Material and methods}




\subsection{System boundary and definition of the functional exergy efficiency}

It is necessary to define the system boundary before evaluating the energy performance. When the system boundary is defined, the exergy or energy balance equation can be formulated. There are several different system boundaries that may be used in estimating the energy performance of a biogas plant [17]. In this study, system boundaries of pyrolysis, oxygen gasification and anaerobic digestion processes of biomasses are shown in Figs. 1-3, respectively, and then their functional exergy efficiencies were defined accordingly.

\subsubsection{Pyrolysis process}

The pyrolysis process of biomass is shown in Fig. 1 and the dashed box is the system boundary (System I). The exergy input of the system is the exergy of biomass $E x_{\mathrm{wb}, \text { total }}$, the exergy input of drying process $\left(E x_{\text {heat } 1, \text { total }}\right)$ and pyrolysis reactor $\left(E x_{\text {hear }, \text { total }}\right)$, and the exergy output of the system is exergy of the syngas ( $\left.E x_{\text {syngas,total }}\right)$. Based on the system boundary, the functional exergy efficiency of pyrolysis process is defined as follows:

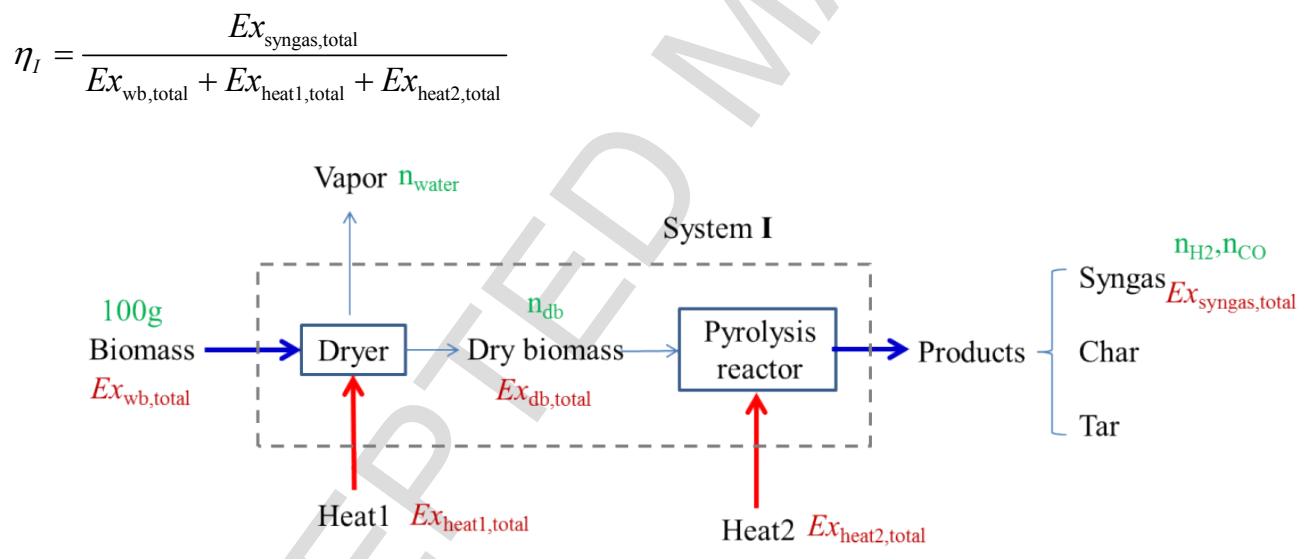

Fig. 1. Schematic diagram of the pyrolysis process of biomass

\subsubsection{Oxygen gasification process}

The oxygen gasification process of biomass is shown in Fig. 2 and the dashed box is the system boundary (System II). The slight different between pyrolysis and oxygen gasification is oxygen added into gasification reactor. The exergy input of the system is the exergy of biomass $E x_{\text {wb,total }}$, the exergy of oxygen $\left(E x_{02, \text { total }}\right)$, the exergy input of drying process $\left(E x_{\text {heat }, \text { total }}\right)$ and gasification reactor 
$\left(E x_{\text {heat, total }}\right)$, and the exergy output of the system is the exergy of the syngas $\left(E x_{\text {syngas,total }}\right)$. Based on the system boundary, the functional exergy efficiency of oxygen gasification process is defined as follows:

$$
\eta_{I I}=\frac{E x_{\text {syngas,total }}}{E x_{\mathrm{wb}, \text { total }}+E x_{\text {O2,total }}+E x_{\text {heat3,total }}+E x_{\text {heat }, \text { total }}}
$$

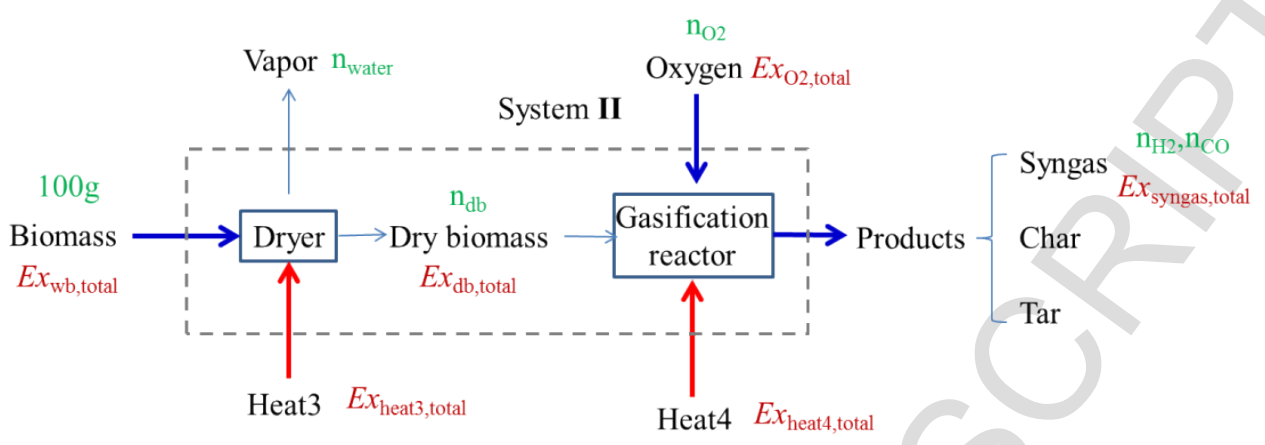

Fig. 2. Schematic diagram of the oxygen gasification process of biomass

\subsubsection{Anaerobic digestion process}

The anaerobic digestion process of biomass is shown in Fig. 3 and the dashed box is the system boundary (System III). The exergy input of the system is the exergy of biomass $E x_{\text {wb,total }}$, the exergy input of anaerobic digestion reactor ( $\left.E x_{\text {heat }, \text { total }}\right)$, and the exergy output of the system is the exergy of the biogas $\left(E x_{\text {biogas,total }}\right)$. Based on the system boundary, the functional exergy efficiency of anaerobic digestion process is defined as follows:

$$
\eta_{I I I}=\frac{E x_{\text {biogas,total }}}{E x_{\text {wb,total }}+E x_{\text {heats,total }}}
$$

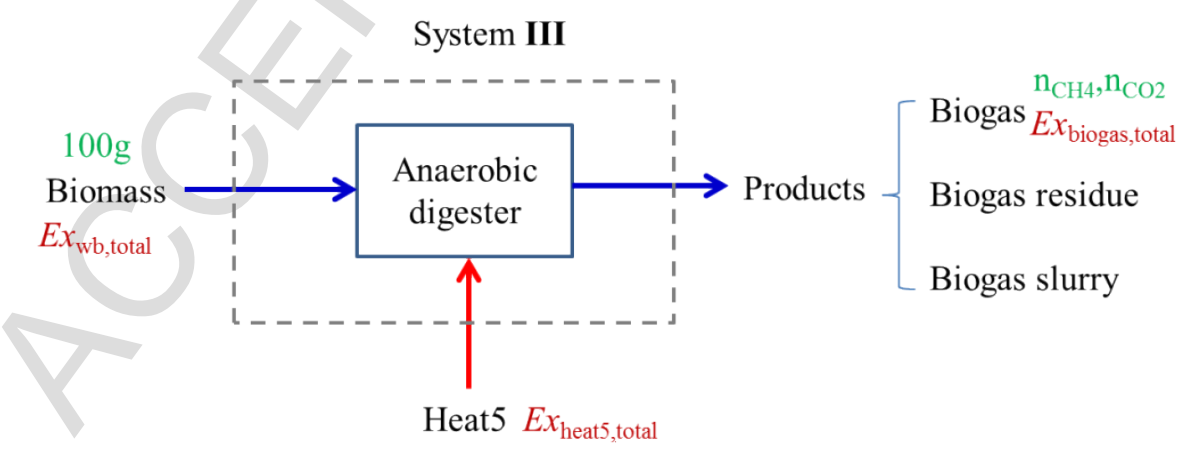

Fig. 3. Schematic diagram of the anaerobic digestion process of biomass

\subsection{Assumptions in process simulation and evaluation}

The following assumptions have been made for facilitating the process simulation and evaluation 
calculations:

(1) The mass of biomass is taken as $100 \mathrm{~g}$ in all utilization pathways of biomasses.

(2) Simulation results of thermochemical and biochemical processes are given based on $100 \mathrm{~g}$ dry biomasses to eliminate the effect of moisture.

(3) For the simulation of thermochemical conversion processes with the Gibbs energy minimization method, char is represented by carbon and ash.

(4) Biogas is assumed to the mixture of $\mathrm{CH}_{4}$ and $\mathrm{CO}_{2}$ as other gases such as $\mathrm{H}_{2} \mathrm{~S}$ are very little, usually less than $1 \%$.

(5) The energy consumptions of the processes such as drying are all expressed as exergy by converting energy into exergy via Carnot efficiency.

(6) The temperature for drying process in thermochemical conversion processes is assumed as $100^{\circ} \mathrm{C}$.

(7) Specific heat capacity of fermentation broth in anaerobic process is assumed to that of water for the total solid of fermentation broth is $5 \%$.

(8) All gaseous components are ideal gas.

\subsection{Process simulation}

\subsubsection{Simulation of thermochemical conversion processes}

The thermochemical conversion processes are simulated by the Gibbs energy minimization method [20, 21] as follows:

$$
\Delta_{\mathrm{f}} H_{\mathrm{m}, i}^{o}+\int_{298.15}^{T} c_{p, i} \mathrm{~d} T+T\left(S_{\mathrm{m}, i}^{o}+\int_{298.15}^{T} \frac{c_{p, i}}{T} \mathrm{~d} T\right)+\mathrm{R} T \ln \left(\frac{n_{i}}{n_{\text {total }}}\right)+\sum_{k} \lambda_{k} a_{i k}=0(i=1,2,3, \ldots, w)
$$

where $\Delta_{\mathrm{f}} H_{\mathrm{m}, i}^{o}, S_{\mathrm{m}, i}^{o}, c_{p, i}$, and R are the standard molar enthalpy of formation, the standard molar entropy, heat capacity, and the universal gas constant, respectively. n notal is the total number of moles of all species $i$. $w$ represents the equilibrium equation refers to each species. As a result of the calculation from Eq. (4), the equilibrium composition $n_{\mathrm{H} 2}$ and $n_{\mathrm{CO}}$ produced from the pyrolysis and oxygen gasification processes are obtained at the given temperature.

According to Eq. (4), the values of standard molar enthalpy of formation $\left(\Delta_{\mathrm{f}} H_{\mathrm{m}}^{o}\right)$, standard molar entropy $\left(S_{\mathrm{m}}^{o}\right)$ and heat capacity $\left(c_{p}\right)$ are necessary for the calculation of the Gibbs energy minimization method. The following equations are used for dry biomass: 


$$
\begin{aligned}
\Delta_{\mathrm{f}} & H_{\mathrm{m}, \text { CHHOONasb }}^{o}=-32.762 \mathrm{C}-141.781 \mathrm{H}-9.258 \mathrm{~S}+87.4\left(\frac{1}{3} \mathrm{C}+\mathrm{H}\right) \quad \mathrm{kJ} \cdot \mathrm{mol}^{-1} \\
S_{m}^{o} & =M \times(0.0055 \mathrm{C}+0.0954 \mathrm{H}+0.0096 \mathrm{O}+0.0098 \mathrm{~N}+0.0138 \mathrm{~S}) \\
& =0.1 \times(0.0055 \mathrm{C}+0.0954 \mathrm{H}+0.0096 \mathrm{O}+0.0098 \mathrm{~N}+0.0138 \mathrm{~S}) \mathrm{kJ} \cdot \mathrm{mol}^{-1} \cdot \mathrm{K}^{-1} \\
C_{p} & =0.001 M c_{p}=0.1(-212.928+4.8567 T) \quad \mathrm{J} \cdot \mathrm{mol}^{-1} \cdot \mathrm{K}^{-1} \\
& =10^{-4}(-212.928+4.8567 T) \quad \mathrm{kJ} \cdot \mathrm{mol}^{-1} \cdot \mathrm{K}^{-1}
\end{aligned}
$$

The simulation of the thermochemical conversion processes is described in detail in section 1.1 in the Appendix.

\subsubsection{Simulation of anaerobic digestion process}

In this study, the PBMP model is used to simulate the anaerobic digestion process, using the following equation:

$$
\begin{aligned}
\operatorname{PBMP}\left(\frac{\mathrm{mLCH}_{4}}{\text { g biomass }}\right) & =(80.4-2.70 \text { Lignin }) \% \times \frac{22400 \times T S \%\left(\frac{\mathrm{C}}{24}+\frac{\mathrm{H}}{8}-\frac{\mathrm{O}}{64}-\frac{3 \mathrm{~N}}{112}\right)}{100} \\
& =(80.4-2.70 \text { Lignin }) \% \times 224 T S \% \times\left(\frac{\mathrm{C}}{24}+\frac{\mathrm{H}}{8}-\frac{\mathrm{O}}{64}-\frac{3 \mathrm{~N}}{112}\right) \mathrm{mL} \cdot \mathrm{g}^{-1}
\end{aligned}
$$

where Lignin means the lignin content of biomass, TS means the total solid of biomass. With the help of Eq.(8), the volume and amount of $\mathrm{CH}_{4}$ can be calculated by Eqs.(9) and (10).

$$
\begin{aligned}
V_{\mathrm{CH} 4} & =100 \times \operatorname{PBMP}\left(\frac{\mathrm{mLCH}_{4}}{\mathrm{~g} \mathrm{wb}}\right) \\
& =(80.4-2.70 \text { Lignin }) \% \times 22400 T S \% \times\left(\frac{\mathrm{C}}{24}+\frac{\mathrm{H}}{8}-\frac{\mathrm{O}}{64}-\frac{3 \mathrm{~N}}{112}\right) \mathrm{mL} \\
n_{\mathrm{CH} 4} & =V_{\mathrm{CH} 4} / 22.4 \times 10^{3} \\
& =(80.4-2.70 \text { Lignin }) \% \times T S \% \times\left(\frac{\mathrm{C}}{24}+\frac{\mathrm{H}}{8}-\frac{\mathrm{O}}{64}-\frac{3 \mathrm{~N}}{112}\right) \mathrm{mol}
\end{aligned}
$$

The simulation of the anaerobic digestion process is described in detail in section 1.2 in the Appendix.

\subsection{Process evaluation}

In this study, the process evaluation of three utilization pathways of biomasses is performed with the use of the functional exergy efficiency. Therefore, it is necessary to calculate the exergy of related substances and processes, and the corresponding equations are provided in Table 1. The derivation of these equations and further details are provided in section 2 of the Appendix. 
Table 1 Exergy calculated in the utilization pathways of biomasses - the important equations.

\begin{tabular}{|c|c|c|c|}
\hline & Pyrolysis & Oxygen gasification & Anaerobic digestion \\
\hline Biomass & \multirow{2}{*}{\multicolumn{3}{|c|}{$E x_{w \mathrm{~b}}=92.072\left(\frac{1}{3} \mathrm{C}+\mathrm{H}\right) \quad \mathrm{kJ} \cdot \mathrm{mol}^{-1}[19]$}} \\
\hline (wb) & & & \\
\hline Dryer & \multicolumn{2}{|c|}{$\begin{array}{l}E x_{\text {heat } 1 \text { total }}=n_{\text {water }} E x_{\text {heat } 1} \\
=5.556(1-T S \%)\left(1-\frac{T_{0}}{T_{D r y}}\right) \times \\
\left(\int_{T_{0}}^{373.15} 0.001 C_{p, \mathrm{H} 2 \mathrm{O}} \mathrm{d} T+40.668\right)\end{array}$} & \\
\hline Reactor & $\begin{array}{l}E x_{\text {heat } 2 \text {,total }} \\
=T S \% \times\left(1-\frac{T_{0}}{T_{I}}\right) \times \\
\int_{T_{0}}^{T_{I}} 0.001 C_{p, \mathrm{db}} \mathrm{d} T\end{array}$ & $\begin{array}{l}E x_{\text {heat } 4 \text {,total }}=E x_{\text {heat } 4,02, \text { total }}+E x_{\text {heat } 4, \mathrm{db}, \text { total }} \\
=T S \% \times\left(1-\frac{T_{0}}{T_{I I}}\right) \int_{T_{0}}^{T_{I I}} 0.001 C_{p, \mathrm{db}} \mathrm{d} T \\
+T S \% \times\left(1-\frac{T_{0}}{T_{I I}}\right) \int_{T 0}^{T_{I I}} 0.001 C_{p, \mathrm{db}} \mathrm{d} T\end{array}$ & $\begin{array}{l}E x_{\text {heat5,total }}=m_{\text {broth }} e_{\text {heat5 }} \\
=0.02 T S \times\left(1-\frac{T_{0}}{T_{I I I}}\right) \times 4.2 \times\left(T_{I I I}-T_{0}\right)\end{array}$ \\
\hline Gas & \multicolumn{2}{|c|}{$\begin{array}{l}E x_{\text {syngas,total }}=E x_{\text {total }}^{p h}+E x_{\text {total }}^{c h}=\left(n_{\mathrm{H} 2} E x_{\mathrm{H} 2}^{p h}+n_{\mathrm{co}} E x^{p h} \mathrm{co}\right) \\
+\left(n_{\mathrm{H} 2}\left(e_{\mathrm{H} 2}^{c h}+R T_{0} \ln x_{\mathrm{H} 2}\right)+n_{\mathrm{CO}}\left(e_{\mathrm{CO}}^{c h}+R T_{0} \ln x_{\mathrm{CO}}\right)\right)\end{array}$} & $E x_{\text {biogas, total }}=n_{\text {total }} E x^{c h}=n_{\mathrm{CH} 4} e_{\mathrm{CH} 4}^{c h}$ \\
\hline
\end{tabular}

where $n_{\mathrm{db}}$ and $E x_{\mathrm{db}}$ represent number of moles and exergy of dry biomass, respectively. $m_{\text {broth }}$ is the mass of fermentation broth in the anaerobic digestion process of biomass.

\subsection{Biomass scenarios}

Low-valued biomass such as straws and manures are very rich worldwide. If these biomasses are not handled properly, they will cause serious environmental pollution problems [4]. Therefore, we selected three kinds of common straws and three kinds of manures [22] in this study to compare different utilization processes of biomass. The physical and ultimate analysis of biomasses is listed in Table 2. It can be seen that the values of TS\% of manures are lower than that of straws, which means that the moisture content of manures is greater than that of straws. It also should be mentioned that the lignin content of dairy manure is the highest. 
Table 2 Physical and ultimate analysis of biomasses

\begin{tabular}{ccccccccccc}
\hline Biomass & Abbreviation & TS\% & VS\% & VS/TS\% & Lignin & Ash & C & H & O & N \\
\hline Chicken manure & CM & 25.9 & 19.5 & 75.3 & 1.6 & 24.7 & 35.9 & 5.1 & 30.5 & 3.4 \\
Dairy manure & DM & 38.5 & 28.8 & 74.8 & 17.4 & 25.2 & 37.6 & 5.1 & 28.9 & 2.8 \\
Swine manure & SM & 30.4 & 22.0 & 72.4 & 4.3 & 27.6 & 34.8 & 4.7 & 30.3 & 2.2 \\
Corn stover & CS & 84.9 & 76.9 & 90.6 & 10.3 & 9.4 & 43.2 & 5.9 & 40.2 & 0.8 \\
Wheat straw & WS & 90.5 & 77.9 & 86.1 & 7.6 & 13.9 & 39.9 & 5.7 & 39.6 & 0.4 \\
Rice straw & $\mathrm{RS}$ & 92.9 & 81.6 & 84.6 & 10.8 & 15.4 & 39.7 & 5.4 & 38.2 & 0.9 \\
\hline
\end{tabular}

\section{Results and Discussion}

\subsection{Process simulation results}

\subsubsection{Simulation results of thermochemical conversion processes}

Although the moisture contents of six biomasses are different, the biomasses were dried before pyrolysis or oxygen gasification reactor. Therefore, the pyrolysis and oxygen gasification processes of same amount (100 $\mathrm{g}$ in this study) of six dry biomasses were calculated via the Gibbs energy minimization method to compare the simulation results, as shown in Fig. 4. The simulation results of pyrolysis and oxygen gasification processes (equivalence ratio (ER) is set as 0.2 in this study, as defined in Eq. (A12) in the Appendix) are respectively represented by the solid line and dash one in Fig. 4 (a) and Fig. 4 (c). The amount of CO produced from the pyrolysis (without grid) and oxygen gasification (with grid) processes at 750,850 and $950{ }^{\circ} \mathrm{C}$ in Fig. 4(a) is shown in detail in Fig. 4(b).

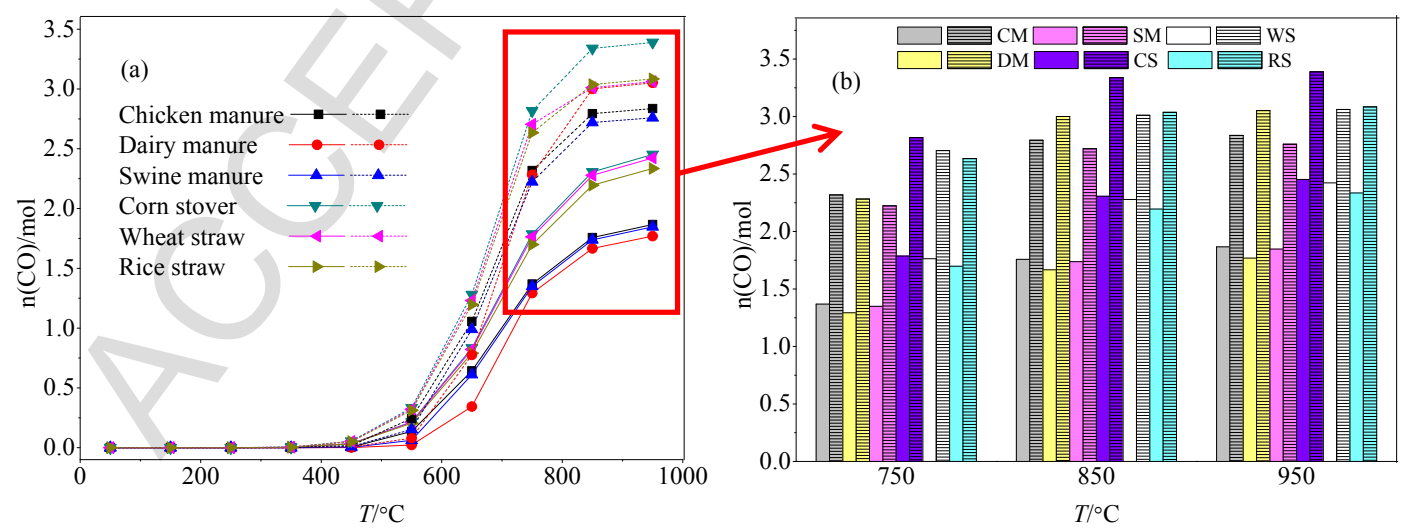




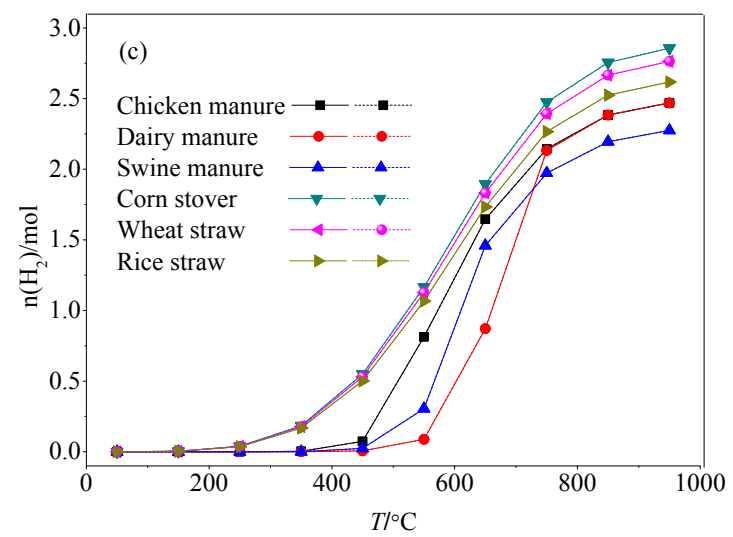

Fig. 4. Simulation results of the pyrolysis (solid line) and oxygen gasification processes (dash line) of six dry biomasses

It can be seen that the amounts of $\mathrm{CO}$ and $\mathrm{H}_{2}$ increase with the temperature increasing in both pyrolysis and oxygen gasification processes in Fig. 4(a) and 4(c). As shown in Fig.4 (a), for the pyrolysis process, the amounts of $\mathrm{CO}$ produced from straws are higher than those from manures. For the same types of biomasses, the amounts of $\mathrm{CO}$ are almost same. As shown in Fig.4 (a) and Fig.4 (b), for the oxygen gasification process, the amounts of $\mathrm{CO}$ produced from six dry biomasses increase dramatically, especially corn stover, which means that the addition of oxygen agent has a significant effect on the amounts of $\mathrm{CO}$ in the products. The amount of $\mathrm{CO}$ of corn stover is the highest in the oxygen gasification process due to its highest carbon content in all biomasses. As shown in Fig.4 (c), for the pyrolysis process, the amounts of $\mathrm{H}_{2}$ produced from straws are higher than those from manures, which is same to the trend of the amounts of CO. Compared with the pyrolysis process, the amounts of $\mathrm{H}_{2}$ obtained from the oxygen gasification process are not changed, which is different to the trend of the amounts of CO. All above simulation results reveal that the high carbon element content of biomass is a necessary condition for its oxygen gasification.

As shown in Fig. 4(c), it should be noted that the amount of $\mathrm{H}_{2}$ produced from both pyrolysis and oxygen gasification processes of dairy manure increases dramatically in the range of 650 to $850{ }^{\circ} \mathrm{C}$, which leads to the reversion between the amount of $\mathrm{H}_{2}$ produced from dairy manure and that from swine manure while the temperature exceeds $750{ }^{\circ} \mathrm{C}$. The phenomenon might be caused by that the lignin content of dairy manure is higher than that of swine manure. This is in accordance with the conclusion that compared with cellulose and hemicellulose, the cracking and deformation of I ignin released out much more $\mathrm{H}_{2}$ at a higher temperature [23]. 
To study the effect of carbon content in biomass on the amount of syngas, the simulation results of the amounts of syngas produced by pyrolysis process of six dry biomasses at the temperature of $850{ }^{\circ} \mathrm{C}$ and their carbon contents are drawn in Fig. 5. It can be seen that the carbon content has a nearly positive effect on the amount of syngas, which means the high carbon content of biomass is also beneficial to its pyrolysis process.

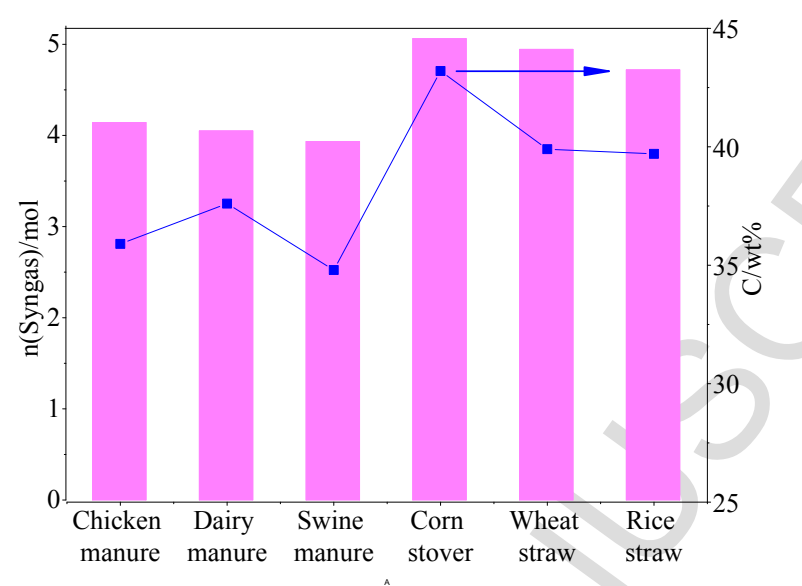

Fig. 5. Relationship between the carbon content in six dry biomasses and the amount of syngas produced by the pyrolysis process at $850^{\circ} \mathrm{C}$

\subsubsection{Simulation results of biochemical conversion process}

Although the moisture content and TS of six biomasses are different, TS of all biomasses in Table 2 is higher than that of fermentation broth (level of 5\% TS is selected in this study), which means that the $\mathrm{TS} \%$ of six biomasses in fermentation broth is same. Therefore, the simulation results of anaerobic digestion process of $100 \mathrm{~g}$ six dry biomasses are set and shown in Fig. 6.

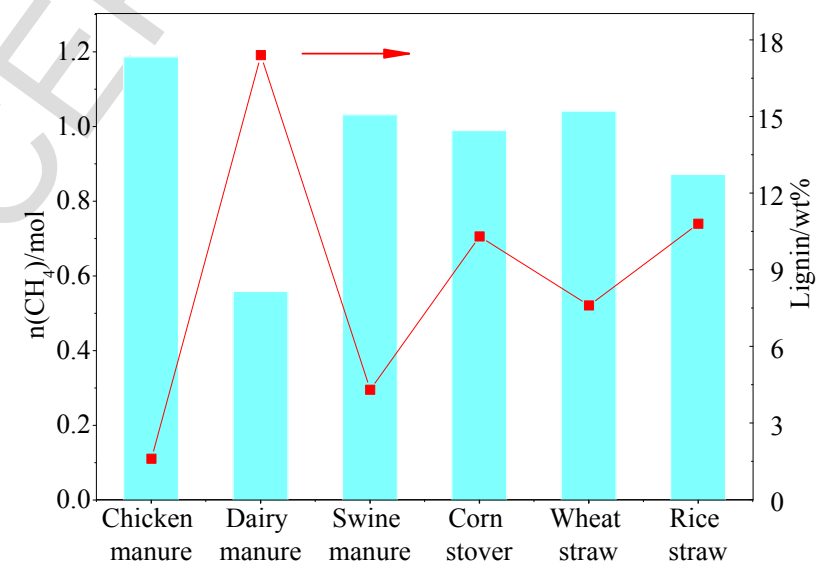

Fig. 6. Simulation results of the anaerobic digestion process of six dry biomasses 
The amounts of $\mathrm{CH}_{4}$ produced from anaerobic digestion of $100 \mathrm{~g}$ straws change little while those from manures vary significantly instead. The amounts of $\mathrm{CH}_{4}$ obtained from chicken manure and dairy manure are the highest and lowest, respectively. The amount of $\mathrm{CH}_{4}$ produced from anaerobic digestion of $100 \mathrm{~g}$ swine manure is similar to that from three straws. According to Eq. (10), the amount of $\mathrm{CH}_{4}$ is related to the lignin and element content. In order to study the effect of lignin content on the amount of $\mathrm{CH}_{4}$, the lignin contents (wt\%) of biomasses are also shown by points connected by a line in Fig. 6. Although the lignin content of swine manure is lower than that of wheat straw, the amount of $\mathrm{CH}_{4}$ obtained from swine manure is also lower. It can be seen that there is a nearly negative relationship between the amounts of $\mathrm{CH}_{4}$ and their lignin contents. All above indicates that the lignin content is the main factor that affects the amounts of $\mathrm{CH}_{4}$ produced compared with element contents.

\subsection{Process evaluation result}

\subsubsection{Pyrolysis process}

According to the relevant calculation formulas of exergy in the section 2.4 , the values of exergy of biomass $E x_{\text {wb,total }}$, the exergy input in the drying process $E x_{\text {heatl,total }}$, the exergy input in the pyrolysis reactor $E x_{\text {heat2,total }}$ and the exergy of syngas product $E x_{\text {syngas,total }}$ in pyrolysis process of six biomasses (100 g) are shown in Fig. 7 (a).
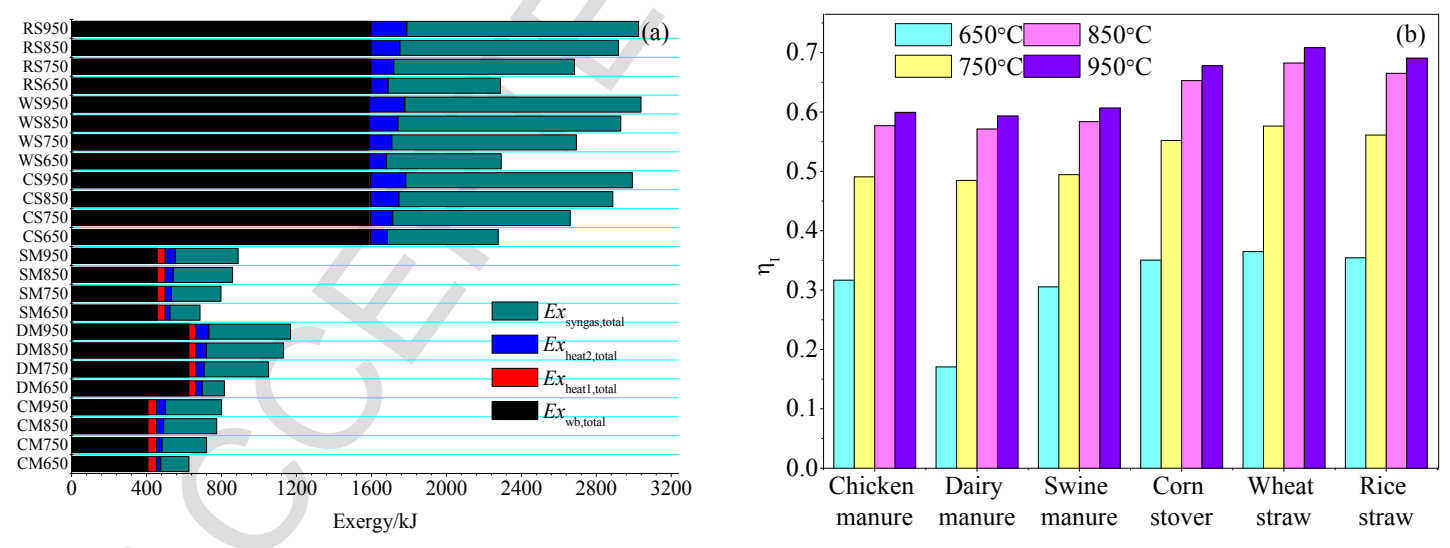

Fig. 7. Exergy (a) in and functional exergy efficiencies (b) of the pyrolysis process of six biomasses at different temperatures

In Fig. 7(a), the numbers following the abbreviated letters indicate the pyrolysis temperature. For example, CM650 means that the pyrolysis process of chicken manure is at $650{ }^{\circ} \mathrm{C}$. As can be seen from Fig. 7(a), for the exergy of biomass $E x_{\text {wb,total }}$ (black bar), the exergies of straws are nearly same, this is 
mainly due to their moisture contents are close to each other. In contrast, the exergies of manures are different, in which the exergy of dairy manure is the largest for its lowest moisture content (highest total solid) in manures. The exergies required for manures are larger than those for straws in the drying process ( $E x_{\text {heatl,total }}$, red bar) due to their moisture contents. The values of the exergies of drying process of straws can be negligible due to their low moisture contents, therefore they (red bar) cannot be found in Fig.7(a). For the same types of biomasses, although the higher the pyrolysis temperature, the more exergy the gas products ( $E x_{\text {syngas,total }}$, dark cyan bar) will be due to the increase of the amount of syngas, the exergy input in the pyrolysis reactor ( $E x_{\text {heat } 2 \text { total }}$, blue bar) also increases as the pyrolysis temperature increases.

The functional exergy efficiencies of pyrolysis process of six biomasses at different temperatures are shown in Fig. 7(b). For the same types of biomasses, the functional exergy efficiencies increase as the pyrolysis temperature increases. Compared with chicken manure and swine manure, the functional exergy efficiency of dairy manure is the lowest at $650{ }^{\circ} \mathrm{C}$ and becomes nearly the same to that of chicken manure and swine manure at 750,850 and $950{ }^{\circ} \mathrm{C}$. This is due to the high lignin content of dairy manure. The cracking and deformation of lignin releases out much more $\mathrm{H}_{2}$ at a higher temperature [23], which leads to higher exergy of syngas produced. It should be mentioned that from 650 to $950{ }^{\circ} \mathrm{C}$ of pyrolysis temperature, the functional exergy efficiencies increase slower and slower. In general, the functional exergy efficiencies of straws are higher than those of manures at different pyrolysis temperatures. At $950{ }^{\circ} \mathrm{C}$, the functional exergy efficiencies of manures and straws can reach about 0.6 and 0.7 , respectively.

The relationship between the functional exergy efficiencies of pyrolysis process of six biomasses at different temperatures and their amounts of syngas produced is shown in Fig. 8. It can be seen that their trends are different. The largest value of functional exergy efficiencies belongs to wheat straw, while the largest amount of syngas is produced by corn stover instead. The functional exergy efficienciy of dairy manure is the lowest and the amount of syngas produced by swine manure is the lowest instead. The different trends between functional exergy efficiencies and their amounts of syngas produced are due to both pyrolysis reaction and the drying process. The latter is very important as different exergies are caused by the varied moisture contents of manures and straws. Moreover, for the same amounts of biomasses, the largest amount of syngas produced does not mean the optimum process for the input of 
energy and the type of biomasses is different. Therefore, a wrong result will appear if the amount of syngas produced is set as the unified protocol.

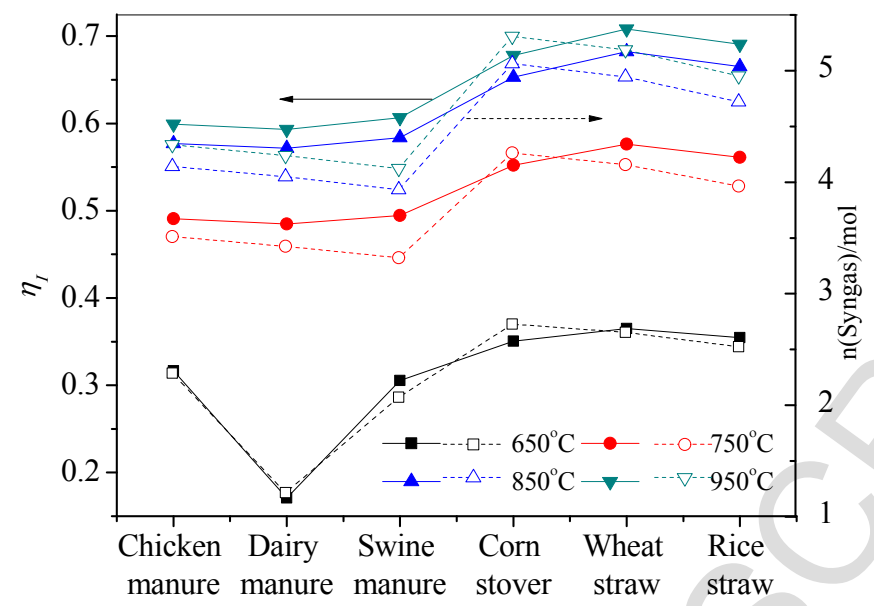

Fig. 8. Relationship between the functional exergy efficiencies (solid line) of pyrolysis process of six biomasses at different temperatures and their amounts of syngas produced (dash line)

\subsubsection{Oxygen gasification process}

According to the relevant calculation formulas of exergy in the section 2.4 , the values of exergy of biomass $E x_{\mathrm{wb}, \text { total }}$, the exergy input in the drying process $E x_{\text {heat3,total }}$, the exergy input in the gasification reactor $E x_{\text {heat,total }}$ and the exergy of syngas product $E x_{\text {syngas,total }}$ in oxygen gasification process of six biomasses (100 g) are shown in Fig. 9.
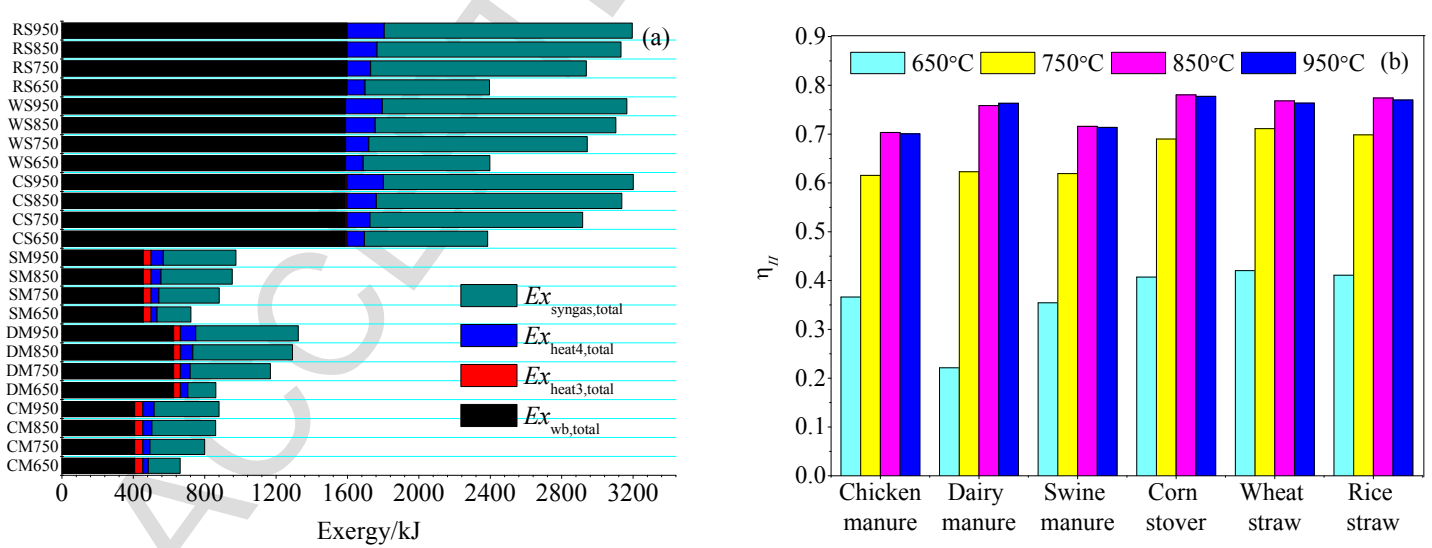

Fig. 9. Exergy (a) in and functional exergy efficiencies (b) of the oxygen gasification process of six biomasses at different temperatures

The numbers following the abbreviated letters indicate the oxygen gasification temperature. Same to 
the pyrolysis process, due to the different moisture contents, the exergies required for manures are larger than those for straws in the drying process $\left(E x_{\text {heat }, \text { total }}\right.$, red bar). The values of the exergies of drying process of straws can be negligible due to their low moisture contents. Therefore, they (red bar) cannot be found in Fig. 9(a). Similar to the pyrolysis process, for the same types of biomasses, the higher the gasification temperature, the more exergy the gas product ( $E x_{\text {syngas,total }}$, dark cyan bar) and the exergy input in the gasification reactor $\left(E x_{\text {heat }, \text { total }}\right.$, blue bar) will be. The difference is that the exergy of the syngas produced from pyrolysis process is more than that from oxygen gasification process. This is mainly due to the increase of the amount of $\mathrm{CO}$ in syngas caused by oxygen agent addition.

The functional exergy efficiencies of oxygen gasification of the six biomasses at different temperatures are shown in Fig. 9(b). Similar to the pyrolysis process, the higher the gasification temperature, the larger the functional exergy efficiencies for the oxygen gasification process of the same types of biomasses. However, the picture changes little after $850^{\circ} \mathrm{C}$, and the functional exergy efficiencies slightly decrease at $950{ }^{\circ} \mathrm{C}$, which is different to the pyrolysis process. This is mainly due to the increase of the exergy required for heating the oxygen added. This illustrates that $850{ }^{\circ} \mathrm{C}$ is suitable temperature for the oxygen gasification process of six biomasses. Above $850{ }^{\circ} \mathrm{C}$, compared with the pyrolysis process, the functional exergy efficiencies of the manures have increased, becoming close to those of straws. In the high temperature region $\left(>850^{\circ} \mathrm{C}\right)$, the functional exergy efficiencies of six biomasses are all more than 0.7 and the maximum values is 0.77 (corn stover).

Unlike what was the case with the pyrolysis process, for manures, the functional exergy efficiencies of dairy manure at 850 and $950^{\circ} \mathrm{C}$ are the lowest in the pyrolysis process but the highest in the oxygen gasification process, as shown in Fig. 9(b) and 10. This is due to the relative high carbon content in dairy manure, which leads to the increase of $\mathrm{CO}$ generated. Compared with the pyrolysis process, the functional exergy efficiencies of the oxygen gasification process are much greater at each temperature, as shown in Fig. 10. This is due to the addition of oxygen at an ER of 0.2 in the oxygen gasification process, so that the amount of $\mathrm{CO}$ in the syngas continues to increase. 


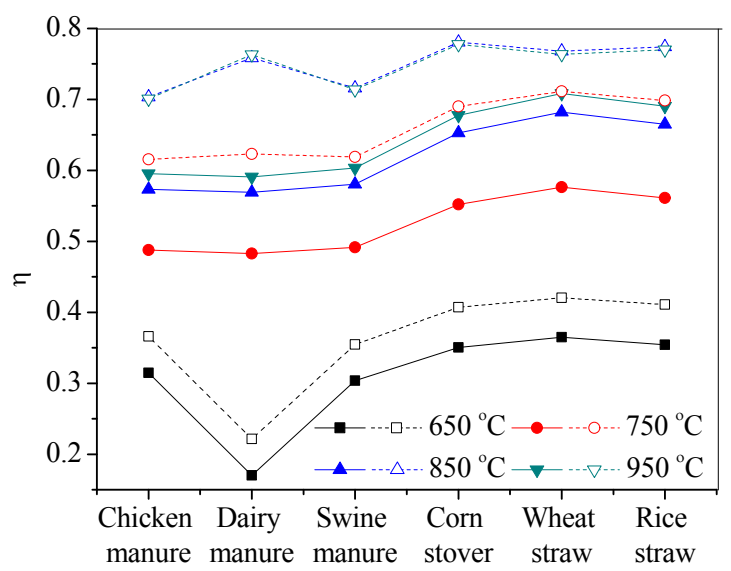

Fig. 10. Comparison of functional exergy efficiencies of pyrolysis process (solid line) and that of the oxygen gasification process (dash line) of six biomasses at different temperatures

\subsubsection{Anaerobic digestion process}

According to the relevant calculation formulas of exergy in the section 2.4 , the values of exergy of biomass $E x_{\text {wb,total }}$, the exergy input in the anaerobic digestion reactor $E x_{\text {heat5,total }}$ and the exergy of biogas product $E x_{\text {biogas,total }}$ in anaerobic digestion process of six biomasses $(100 \mathrm{~g})$ are shown in Fig. 11 (a). The exergy input to the anaerobic digestion reactor ( $E x_{\text {heat5,total }}$, red bar) is almost negligible due to the temperature difference of $12{ }^{\circ} \mathrm{C}$ between anaerobic digestion temperature and ambient one. Although the exergy of chicken manure and swine manure are less than dairy manure, more biogas is generated than dairy manure. This phenomenon is mainly due to the high lignin content in dairy manure, resulting in a decrease in the degradation rate of dairy manure and hence the exergy of gas product is low. The exergy of the biogas of anaerobic digestion of wheat straw is more than that of corn stover and rice straw is also due to its low lignin content.
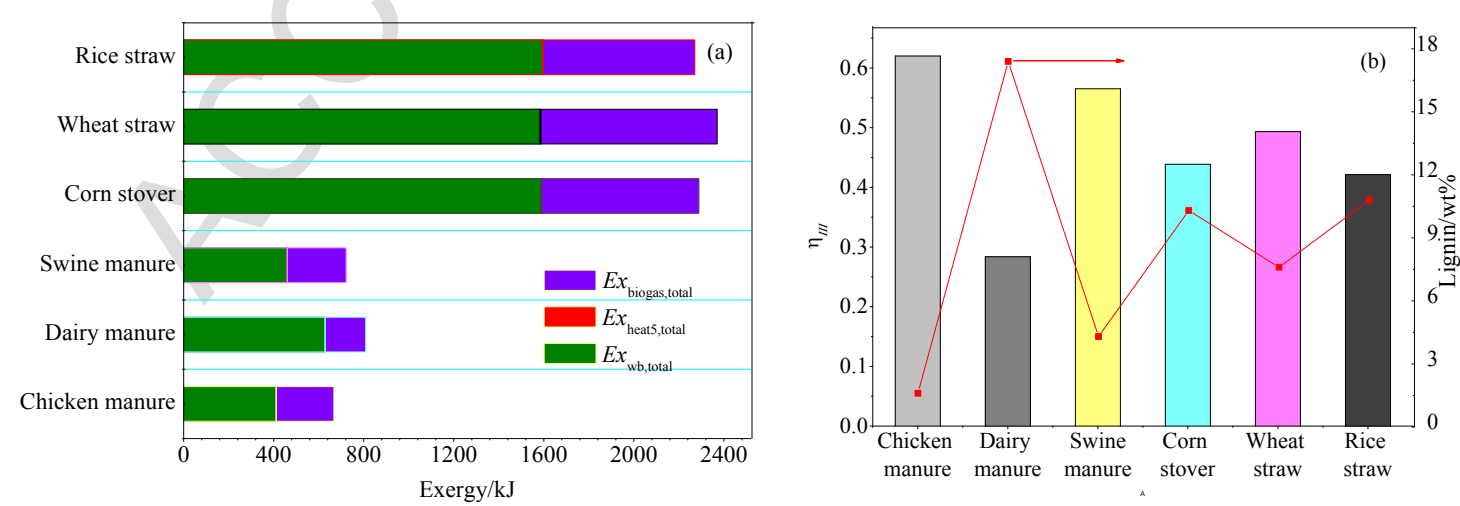

Fig. 11. Exergy (a) in and functional exergy efficiencies (b) of the anaerobic digestion process of six 
biomasses

The low exergy for biogas obtained from dairy manure can also be seen from the comparison of the functional exergy efficiencies of anaerobic digestion process of six biomasses shown in Fig. 11(b). The functional exergy efficiencies of the anaerobic digestion process of manures except dairy manure are higher than those of straws. The highest and lowest functional exergy efficiency is the anaerobic digestion process of chicken manure (0.6) and dairy manure (0.29). Among the three straws, the functional exergy efficiencies of anaerobic digestion process of rice straw and corn stover is close to each other, the functional exergy efficiency of wheat straw shows the higher value. Therefore, the chicken manure is more suitable to be used as the feedstock of anaerobic digestion due to the highest functional exergy efficiency. Manures except dairy manure are better than straws while used as feedstock of anaerobic digestion. The relationship between lignin content and functional exergy efficiency is also studied and shown in Fig. 11(b). It can be seen that there are also a nearly negative relationship between the values of functional exergy efficiencies and their lignin contents. The reason is that the exergy input of anaerobic digestion reactor is the only one needed and the value can be neglected. Therefore, the trend of functional exergy efficiencies is same to that of the amount of biogas produced by different biomasses.

Compared with the pyrolysis and oxygen gasification processes, the functional exergy efficiencies of anaerobic digestion are lower than those of the pyrolysis and gasification processes at the temperature above $850{ }^{\circ} \mathrm{C}$ for the organic matter entering the biogas residue, which is mainly due to the lignin content in biomass cannot be degradable in anaerobic digestion process but can be converted in thermochemical conversion processes at high temperatures. Therefore, an important route of improving the biogas production of the anaerobic digestion process is to reduce the lignin content such as via pretreatment of biomass [24].

\section{Conclusions}

With the help of the composition of biomasses, utilization pathways of biomasses are simulated and evaluated successfully based on predicted thermodynamic data. The conclusions are listed as follows:

(1) For the pyrolysis and oxygen gasification processes, the trend of the amount of syngas produced is different to the functional exergy efficiency, while the trend of the amount of biogas produced and 
the functional exergy efficiency is the same for anaerobic digestion process.

(2) According to the functional exergy efficiencies, straws are more suitable than manures used in the pyrolysis process for their lower moisture content. The higher the temperature $\left(<950{ }^{\circ} \mathrm{C}\right)$, the greater the functional exergy efficiencies are.

(3) Functional exergy efficiencies of the oxygen gasification process of six biomasses are all higher than those of the pyrolysis process. A suitable temperature for the oxygen gasification process of six biomasses is $850{ }^{\circ} \mathrm{C}$. The functional exergy efficiencies of dairy manure at 850 and $950{ }^{\circ} \mathrm{C}$ show the lowest value in the pyrolysis process but the highest value in the oxygen gasification process. In the high temperature region $\left(>850{ }^{\circ} \mathrm{C}\right)$, compared with the pyrolysis process, the functional exergy efficiencies of the manures have increased, becoming close to those of straws. The functional exergy efficiencies of six biomasses are all more than 0.7 and the maximum values is 0.77 (corn stover).

(4) For the anaerobic digestion process, the functional exergy efficiencies of straws are generally lower than that of manures. Manures with low lignin content (chicken manure in this study) are more suitable as the feedstock of anaerobic digestion process. The functional exergy efficiencies of anaerobic digestion are lower than those of the pyrolysis and gasification processes at temperature above $850^{\circ} \mathrm{C}$.

The significant of this study is to propose a method to compare different utilization pathways of various biomasses based on the composition of biomasses directly.

\section{Acknowledgements}

This work was financially supported by the National Key Research and Development Program of China (2017YFD0401301), National Natural Science Foundation of China $(21878337,21676291$, 21406272, 21476106), Jiangsu Agriculture Science and Technology Innovation Fund (JASTIF) (CX(18)3039), the program of China Scholarship Council (201707060006) and the Fundamental Research Funds for the Central Universities (2632017ZD01) . 


\section{Appendix}

\section{Process simulation}

\subsection{Simulation of thermochemical conversion}

\subsubsection{Input of drying process}

Based on the assumption that the mass of biomass was taken as $100 \mathrm{~g}$ in all utilization pathways of biomasses, the mass of dry biomass (db) and water were calculated by Eqs. (A.1) and (A.2), respectively.

$$
\begin{aligned}
& m_{\mathrm{db}}=m_{\mathrm{wb}} \times T S \%=T S \quad \mathrm{~g} \\
& m_{\mathrm{water}}=m_{\mathrm{wb}} \times(1-T S \%)=100-T S \quad \mathrm{~g}
\end{aligned}
$$

where $m_{\mathrm{db}}, m_{\mathrm{wb}}$ and $m_{\mathrm{water}}$ are the mass of dry biomass, biomass and water, respectively. TS represents total solid in biomass.

Due to the fact that the calculation of heat capacity, standard molar enthalpy of formation and so on is based on mole, the mass of dry biomass and water was transferred to mole basis. It should be noted that the molecular weight of dry biomass was taken as $100 \mathrm{~g} \cdot \mathrm{mol}^{-1}$ and their chemical formula were determined accordingly in this study.

$$
\begin{aligned}
& n_{\mathrm{db}}=m_{\mathrm{db}} / 100=T S / 100=T S \% \text { mol } \\
& n_{\text {water }}=m_{\text {water }} / 18=(100-T S) / 18=5.556(1-T S \%) \quad \mathrm{mol}
\end{aligned}
$$

where $n_{\mathrm{db}}$ and $n_{\text {water }}$ are the moles of dry biomass and water, respectively.

\subsubsection{Gibbs energy minimization}

The total Gibbs energy of the system is written as follows [20, 21]:

$$
G_{T, p}^{t}=g\left(n_{1}, n_{2}, n_{3}, \ldots, n_{i}, \ldots, n_{w}\right) \quad(i=1,2,3, \ldots, w)
$$

where $G_{T, p}^{t}$ is the total Gibbs energy of the system and $n_{i}$ is referred to each species (mol). The problem is to find the set of $n_{i}$ for which the total Gibbs energy of system is minimized. The material balance for each elements present in the system is given by

$$
\sum_{i} n_{i} a_{i k}=A_{k}
$$

where $a_{i k}$ is the number of atoms of the $k$ th element present in each molecule of the chemical species $i$, $A_{k}$ is the total number of atomic masses of the $k$ th element in the system. 
The Gibbs energy of the system is minimized with the Lagrange method by using the elemental mass balances as subsidiary constraints. Therefore, a new function is derived by adding Eqs. (A.5) and (A.6),

$$
F=G_{T, p}^{t}+\sum_{k} \lambda_{k}\left(\sum_{i} n_{i} a_{i k}-A_{k}\right)
$$

where $\lambda_{k}$ are the Lagrange multipliers. The minimum value of $F$ is occurred when the partial derivative with respect to each species approaches to zero at specified temperature and pressure,

$$
\frac{\partial F}{\partial n_{i}}=\frac{\partial G_{T, p}^{t}}{\partial n_{i}}+\sum_{k} \lambda_{k} a_{i k}=0
$$

where $\frac{\partial G_{T, p}^{t}}{\partial n_{i}}$ is known as chemical potential $\left(\mu_{i}\right)$, therefore, the following equation can be obtained.

$$
\mu_{i}+\sum_{k} \lambda_{k} a_{i k}=0
$$

The chemical potential is defined as [20,21],

$$
\begin{aligned}
& \mu_{i}=\Delta_{\mathrm{f}} G_{\mathrm{m}, i}+\mathrm{R} T \ln \left(\frac{n_{i}}{n_{\text {total }}}\right)=\Delta_{\mathrm{f}} H_{\mathrm{m}, i}+T S_{\mathrm{m}, i}+\mathrm{R} T \ln \left(\frac{n_{i}}{n_{\text {total }}}\right) \\
& =\Delta_{\mathrm{f}} H_{\mathrm{m}, i}^{o}+\int_{298.15}^{T} c_{p i} \mathrm{~d} T+T\left(S_{\mathrm{m}, i}^{o}+\int_{298.15}^{T} \frac{c_{p i}}{T} \mathrm{~d} T\right)+\mathrm{R} T \ln \left(\frac{n_{i}}{n_{\text {total }}}\right)
\end{aligned}
$$

where $\Delta_{\mathrm{f}} H_{\mathrm{m}, i}^{o}, \quad S_{\mathrm{m}, i}^{o}, \quad c_{p i}, \mathrm{R}$ are the standard molar enthalpy of formation, the standard molar entropy, heat capacity, and the universal gas constant respectively. $n_{\text {total }}$ means the total mole of all species $i$.

Putting Eq. (A.10) in Eq. (A.9) gives,

$$
\Delta_{\mathrm{f}} H_{\mathrm{m}, i}^{o}+\int_{298.15}^{T} c_{p, i} \mathrm{~d} T+T\left(S_{\mathrm{m}, i}^{o}+\int_{298.15}^{T} \frac{c_{p, i}}{T} \mathrm{~d} T\right)+\mathrm{R} T \ln \left(\frac{n_{i}}{n_{\text {total }}}\right)+\sum_{k} \lambda_{k} a_{i k}=0 \quad(i=1,2,3, \ldots, w)
$$

The above equation represents $w$ equilibrium equations referring to each species present in the system. As a result of the calculation by Eq. (4), the equilibrium composition $n_{i}$ (such as $n_{\mathrm{H}_{2}}$ and $n_{\mathrm{CO}}$ obtained from pyrolysis and oxygen gasification in this study) of the multi-phase system at given temperature is obtained.

The thermodynamic equilibrium of coal gasification was analyzed via the Gibbs energy minimization method and the detailed calculation steps were shown [21]. The Equilibrium amount of products of pyrolysis and oxygen gasification calculated by the Gibbs energy minimization method was 
rewritten for biomass as follows:

The calculation is structured using the species in the product mixture taken from literature [25] and they are presented in Table A.1.

Table A.1 List of species considered in the calculation

\begin{tabular}{ccccccccccccc}
\hline Species & \multicolumn{1}{c}{$\mathrm{C}^{2} \mathrm{C}(\mathrm{g})$} & $\mathrm{CH}$ & $\mathrm{CH}_{2}$ & $\mathrm{CH}_{3}$ & $\mathrm{CH}_{4}$ & $\mathrm{C}_{2} \mathrm{H}_{2}$ & $\mathrm{C}_{2} \mathrm{H}_{4}$ & $\mathrm{C}_{2} \mathrm{H}_{6}$ & $\mathrm{C}_{3} \mathrm{H}_{8}$ & $\mathrm{H}$ & $\mathrm{H}_{2}$ \\
$\mathrm{O}$ & $\mathrm{O}_{2}$ & $\mathrm{CO}$ & $\mathrm{CO}_{2}$ & $\mathrm{OH}$ & $\mathrm{H}_{2} \mathrm{O}$ & $\mathrm{H}_{2} \mathrm{O}_{2}$ & $\mathrm{HCO}$ & $\mathrm{HO}_{2}$ & $\mathrm{~N}$ & $\mathrm{~N}_{2}$ \\
$\mathrm{NCO}$ & $\mathrm{NH}$ & $\mathrm{NH}_{2}$ & $\mathrm{NH}_{3}$ & $\mathrm{~N}_{2} \mathrm{O}$ & $\mathrm{NO}$ & $\mathrm{NO}_{2}$ & $\mathrm{CN}$ & $\mathrm{HCN}$ & $\mathrm{HCNO}$ & $\mathrm{S}(\mathrm{g})$ \\
$\mathrm{S}_{2}(\mathrm{~g})$ & $\mathrm{SO}$ & $\mathrm{SO}_{2}$ & $\mathrm{SO}_{3}$ & $\mathrm{COS}$ & $\mathrm{CS}$ & $\mathrm{CS}_{2}$ & $\mathrm{HS}$ & $\mathrm{H}_{2} \mathrm{~S}$ & $\mathrm{C}(\mathrm{s})$ & $\mathrm{S}(\mathrm{s})$ \\
\hline
\end{tabular}

Therefore the global reaction for both pyrolysis and oxygen gasification of dry biomasses (represented by $\mathrm{C}_{x} \mathrm{H}_{y} \mathrm{O}_{z} \mathrm{~N}_{a} \mathrm{~S}_{b}$ ) can be written as,

$$
\mathrm{C}_{x} \mathrm{H}_{y} \mathrm{O}_{z} \mathrm{~N}_{a} \mathrm{~S}_{b}+\mathrm{ER}\left[\left(x+\frac{y}{4}-\frac{z}{2}+b\right) \mathrm{O}_{2}(g)\right] \rightarrow \text { Table A1 }
$$

where $x, y, z, a, b$ are respectively the moles of carbon $(\mathrm{C})$, hydrogen $(\mathrm{H})$, oxygen $(\mathrm{O})$, nitrogen $(\mathrm{N})$ and sulfur (S) in $100 \mathrm{~g}$ of dry biomass. $x=\mathrm{C} / 12, y=\mathrm{H}, z=\mathrm{O} / 16, a=\mathrm{N} / 14$, and $b=\mathrm{S} / 32$ for unit conversion. $\mathrm{C}$, $\mathrm{H}, \mathrm{N}, \mathrm{S}$ are determined by ultimate analysis $(\mathrm{wt} \%, \mathrm{db})$, and the $\mathrm{O}$ content usually serves as an indicator to differentiate the sum of the percentages of $\mathrm{C}, \mathrm{H}, \mathrm{N}, \mathrm{S}$ and that of the ash $(\mathrm{O}=100-\mathrm{C}-\mathrm{H}-\mathrm{N}-\mathrm{S}-\mathrm{Ash})$.

ER means equivalence ratio and is defined as follows.

$$
E R=\frac{\text { Moles of actual oxygen assumption }}{\text { Stoichiometric ratio }}
$$

where the stoichiometric ratio is defined as the moles of oxygen needed to combust 1 mole of biomass, $x+\frac{y}{4}-\frac{z}{2}+b \mathrm{~mol}$ in this study. The values of ER for pyrolysis process and oxygen gasification process are 0 and $0 \sim 1$, respectively.

All the species are combination of five basic elements i.e. carbon, hydrogen, oxygen, nitrogen and sulfur. Therefore, initially five constrain mass balances are written that represent each element conservation in the system, as given by Eq. (A.6).

Carbon balance:

$$
n_{\mathrm{C}}+n_{\mathrm{CH}}+n_{\mathrm{CH}_{2}}+n_{\mathrm{CH}_{3}}+n_{\mathrm{CH}_{4}}+2 n_{\mathrm{C}_{2} \mathrm{H}_{2}}+\ldots+n_{\mathrm{CS}_{2}}+n_{\mathrm{CS}}=x
$$

Hydrogen balance:

$$
n_{\mathrm{CH}}+2 n_{\mathrm{CH}_{2}}+3 n_{\mathrm{CH}_{3}}+4 n_{\mathrm{CH}_{4}}+2 n_{\mathrm{C}_{2} \mathrm{H}_{2}}+\ldots+n_{\mathrm{HS}}+2 n_{\mathrm{H}_{2} \mathrm{~S}}=y
$$


Oxygen balance:

$$
n_{\mathrm{O}}+2 n_{\mathrm{O} 2}+n_{\mathrm{CO}}+2 n_{\mathrm{CO} 2}+n_{\mathrm{OH}}+\ldots+3 n_{\mathrm{SO} 3}+n_{\mathrm{COS}}=z+2 E R\left(x+\frac{y}{4}-\frac{z}{2}+b\right)
$$

Nitrogen balance:

$$
n_{\mathrm{N}}+2 n_{\mathrm{N} 2}+n_{\mathrm{NCO}}+n_{\mathrm{NH}}+n_{\mathrm{NH} 2}+\ldots+n_{\mathrm{HCN}}+n_{\mathrm{HCNO}}=a
$$

Sulfur balance:

$$
n_{\mathrm{S}}+2 n_{\mathrm{s} 2}+n_{\mathrm{SO}}+n_{\mathrm{SO}_{2}}+n_{\mathrm{SO}_{3}}+\ldots+n_{\mathrm{H} 2 \mathrm{~S}}+n_{\mathrm{S}(\mathrm{s})}=b
$$

Now using Eq. (4) a set of equations are written for each species present in the products. A formulation for few species are shown below,

For methane:

$$
\Delta_{\mathrm{f}} H_{\mathrm{m}, \mathrm{CH} 4}^{o}+\int_{298.15}^{T} c_{p, \mathrm{CH} 4} \mathrm{~d} T+T\left(S_{\mathrm{m}, \mathrm{CH} 4}^{o}+\int_{298.15}^{T} \frac{c_{p, \mathrm{CH} 4}}{T} \mathrm{~d} T\right)+\mathrm{R} T \ln \left(\frac{n_{\mathrm{CH}_{4}}}{n_{\text {total }}}\right)+\left(\lambda_{1}+4 \lambda_{2}\right)=0
$$

For hydrogen:

$$
\Delta_{\mathrm{f}} H_{\mathrm{m}, \mathrm{H} 2}^{o}+\int_{298.15}^{T} c_{p, \mathrm{H} 2} \mathrm{~d} T+T\left(S_{\mathrm{m}, \mathrm{H} 2}^{o}+\int_{298.15}^{T} \frac{c_{p, \mathrm{H} 2}}{T} \mathrm{~d} T\right)+\mathrm{R} T \ln \left(\frac{n_{\mathrm{H} 2}}{n_{\text {total }}}\right)+\left(2 \lambda_{2}\right)=0
$$

For carbon monoxide:

$$
\Delta_{\mathrm{f}} H_{\mathrm{m}, \mathrm{CO}}^{o}+\int_{298.15}^{T} c_{p, \mathrm{CO}} \mathrm{d} T+T\left(S_{\mathrm{m}, \mathrm{CO}}^{o}+\int_{298.15}^{T} \frac{c_{p, \mathrm{CO}}}{T} \mathrm{~d} T\right)+\mathrm{R} T \ln \left(\frac{n_{\mathrm{CO}}}{n_{\text {total }}}\right)+\left(\lambda_{1}+\lambda_{3}\right)=0
$$

For solid C:

$$
\Delta_{\mathrm{f}} H_{\mathrm{m}, \mathrm{C}}^{o}+\int_{298.15}^{T} c_{p, \mathrm{C}} \mathrm{d} T+T\left(S_{\mathrm{m}, \mathrm{c}}^{o}+\int_{298.15}^{T} \frac{c_{p, \mathrm{C}}}{T} \mathrm{~d} T\right)+\mathrm{R} T \ln \left(\frac{n_{\mathrm{C}}}{n_{\text {total }}}\right)+\lambda_{1}=0
$$

$n_{\text {total }}$ in Eqs. (A.18)-(A.21) means the total mole of all species and can be calculated by,

$$
n_{\mathrm{total}}=n_{\mathrm{C}}+n_{\mathrm{CH}}+n_{\mathrm{CH}_{2}}+n_{\mathrm{CH}_{3}}+n_{\mathrm{CH}_{4}}+n_{\mathrm{C}_{2} \mathrm{H} 2}+\ldots+n_{\mathrm{S}(\mathrm{s})}+n_{\mathrm{C}(\mathrm{s})}
$$

The model is comprised of 49 unknown that include 44 product species moles, 5 Lagrange multipliers $\left(\lambda_{1}, \lambda_{2}, \lambda_{3}, \lambda_{4}\right.$ and $\left.\lambda_{5}\right)$. Therefore, in order to calculate the unknowns, 49 equations are required. 5 equations come from the mass balance of elements from Eqs. (A.13)-(A.17), 44 equations are included using Eq. (4) and demonstration of these equations are presented in Eqs. (A.18)-(A.21).

\subsubsection{Estimating thermodynamic data of dry biomass}


According to Eq. (4), the values of standard molar enthalpy of formation $\left(\Delta_{\mathrm{f}} H_{\mathrm{m}}^{o}\right)$, standard molar entropy $\left(S_{\mathrm{m}}^{o}\right)$ and heat capacity $\left(c_{p}\right)$ of dry biomass are necessary to the calculation by the Gibbs energy minimization method.

(1) Estimating standard molar enthalpy of formation $\left(\Delta_{\mathrm{f}} H_{\mathrm{m}}^{o}\right)$

The combustion reaction between dry biomass and oxygen in oxygen bomb calorimeter is described by:

$$
\mathrm{C}_{x} \mathrm{H}_{y} \mathrm{O}_{z} \mathrm{~N}_{a} \mathrm{~S}_{b}+\left(x+\frac{y}{4}-\frac{z}{2}+b\right) \mathrm{O}_{2}(g) \rightarrow x \mathrm{CO}_{2}(g)+\frac{y}{2} \mathrm{H}_{2} \mathrm{O}(l)+\frac{a}{2} \mathrm{~N}_{2}(g)+b \mathrm{SO}_{2}(g)
$$

The value of energy change of combustion reaction in oxygen bomb calorimeter is higher heat value $\left(H H V, \mathrm{~kJ} \cdot \mathrm{kg}^{-1}\right.$, based on dry biomass), then,

$$
\begin{aligned}
-0.001 M \times H H V & =x \Delta_{\mathrm{f}} H_{\mathrm{m}, \mathrm{CO} 2}^{o}+\frac{y}{2} \Delta_{\mathrm{f}} H_{\mathrm{m}, \mathrm{H} 20(\mathrm{I})}^{o}+\frac{a}{2} \Delta_{\mathrm{f}} H_{\mathrm{m}, \mathrm{N} 2}^{o}+b \Delta_{\mathrm{f}} H_{\mathrm{m}, \mathrm{SO2} 2}^{o} \\
& -\Delta_{\mathrm{f}} H_{\mathrm{m}, \mathrm{C} \mathrm{CH} \mathrm{H} \mathrm{O} \mathrm{N} \mathrm{NaSb}}^{o}-\left(x+\frac{y}{4}-\frac{z}{2}+b\right) \Delta_{\mathrm{f}} H_{\mathrm{m}, \mathrm{O} 2}^{o}
\end{aligned}
$$

where $M$ is molecular weight of dry biomass, $100 \mathrm{~g} \cdot \mathrm{mol}^{-1} . \Delta_{\mathrm{f}} H_{\mathrm{m}, \mathrm{CH} \mathrm{H}, \mathrm{O} 2 \mathrm{NaSb} b}^{o}, \Delta_{\mathrm{f}} H_{\mathrm{m}, \mathrm{CO} 2}^{o}, \quad \Delta_{\mathrm{f}} H_{\mathrm{m}, \mathrm{H} 2 \mathrm{O}(\mathrm{l})}^{o}$, $\Delta_{\mathrm{f}} H_{\mathrm{m}, \mathrm{N} 2}^{o}, \quad \Delta_{\mathrm{f}} H_{\mathrm{m}, \mathrm{OO2}}^{o}$ and $\Delta_{\mathrm{f}} H_{\mathrm{m}, \mathrm{O} 2}^{o}$ are standard molar enthalpy of formation of dry biomass, carbon dioxide, liquid water, nitrogen, sulfur dioxide and oxygen, then,

$$
\begin{aligned}
\Delta_{\mathrm{f}} H_{\mathrm{m}, \mathrm{CXH}, \mathrm{O}=\mathrm{N} a \mathrm{aSb}}^{o} & =x \Delta_{\mathrm{f}} H_{\mathrm{m}, \mathrm{CO2}}^{o}+\frac{y}{2} \Delta_{\mathrm{f}} H_{\mathrm{m}, \mathrm{H} 20(1)}^{o}+\frac{a}{2} \Delta_{\mathrm{f}} H_{\mathrm{m}, \mathrm{N} 2}^{o}+b \Delta_{\mathrm{f}} H_{\mathrm{m}, \mathrm{SO2}}^{o} \\
& -\left(x+\frac{y}{4}-\frac{z}{2}+b\right) \Delta_{\mathrm{f}} H_{\mathrm{m}, \mathrm{O} 2}^{o}+0.001 M \times H H V
\end{aligned}
$$

Where $\Delta_{\mathrm{f}} H_{\mathrm{m}, \mathrm{CO2}}^{o}, \Delta_{\mathrm{f}} H_{\mathrm{m}, \mathrm{H} 2(\mathrm{I})}^{o}, \Delta_{\mathrm{f}} H_{\mathrm{m}, \mathrm{N} 2}^{o}, \Delta_{\mathrm{f}} H_{\mathrm{m}, \mathrm{SO2}}^{o}$ and $\Delta_{\mathrm{f}} H_{\mathrm{m}, \mathrm{O} 2}^{o}$ can be looked up from data handbook [26], and their values were listed in Table A.2. $H H V$ can be given by experimental data or prediction model. For the types and composition of biomasses varied, $H H V$ was estimated by the high accurate

\begin{tabular}{|c|c|c|c|c|c|}
\hline Substance & $\mathrm{CO}_{2}$ & $\mathrm{H}_{2} \mathrm{O}$ & $\mathrm{N}_{2}$ & $\mathrm{SO}_{2}$ & $\mathrm{O}_{2}$ \\
\hline$\Delta_{\mathrm{f}} H_{\mathrm{m}, i} / \mathrm{kJ} \mathrm{mol}^{-1}$ & -393.505 & -285.830 & 0 & -296.813 & 0 \\
\hline$\Delta_{\mathrm{f}} H_{\mathrm{m}, \mathrm{CXH} \mathrm{O} \mathrm{O} \mathrm{N} \mathrm{NS} b}^{o}=$ & $\begin{array}{l}05 x-142 \\
05 x-142\end{array}$ & $\begin{array}{l}296.813 b \\
296.813 b-\end{array}$ & $\begin{array}{l}01 \times 8 \\
\times\left(\frac{1}{3}\right.\end{array}$ & $+\mathrm{H})$ & (A.26) \\
\hline
\end{tabular}
model proposed in our previous study [18] and the equation was listed as follows.

$$
H H V=874.08\left(\frac{1}{3} \mathrm{C}+\mathrm{H}\right) \quad \mathrm{kJ} \cdot \mathrm{kg}^{-1}
$$

Table A.2 Thermodynamic data of substances involved in the calculation of biomass's enthalpy 
According to the definition of $x, y$ and $b$, the final calculation equation of standard molar enthalpy of formation of dry biomass was obtained.

$$
\Delta_{\mathrm{f}} H_{\mathrm{m}, \mathrm{C} \text { HHOOZNaSb }}^{o}=-32.762 \mathrm{C}-141.781 \mathrm{H}-9.258 \mathrm{~S}+87.4\left(\frac{1}{3} \mathrm{C}+\mathrm{H}\right) \quad \mathrm{kJ} \cdot \mathrm{mol}^{-1}
$$

It has been verified that $H H V$ can be predicted by Eq. (A.25) with the element contents in dry biomass in our previous study [18], so it is reasonable and accurate that the standard molar enthalpy of formation of dry biomass is calculated by Eq. (5) with element contents.

(2) Estimating standard molar entropy $S_{m}^{o}$

Song et al. [27] developed a relationship between standard entropy and composition of 27 types of solid biomolecules and proposed the specific entropy of dry biomass as follows.

$$
s^{o}=0.0055 \mathrm{C}+0.0954 \mathrm{H}+0.0096 \mathrm{O}+0.0098 \mathrm{~N}+0.0138 \mathrm{~S} \quad \mathrm{~kJ} \cdot \mathrm{kg}^{-1} \cdot \mathrm{K}^{-1}
$$

In this study, the calculation is based on mole, then Eq. (A.27) was expressed as:

$$
\begin{aligned}
S_{m}^{o} & =M \times(0.0055 \mathrm{C}+0.0954 \mathrm{H}+0.0096 \mathrm{O}+0.0098 \mathrm{~N}+0.0138 \mathrm{~S}) \\
& =100 \times(0.0055 \mathrm{C}+0.0954 \mathrm{H}+0.0096 \mathrm{O}+0.0098 \mathrm{~N}+0.0138 \mathrm{~S}) \quad \mathrm{J} \cdot \mathrm{mol}^{-1} \cdot \mathrm{K}^{-1} \\
& =0.1 \times(0.0055 \mathrm{C}+0.0954 \mathrm{H}+0.0096 \mathrm{O}+0.0098 \mathrm{~N}+0.0138 \mathrm{~S}) \quad \mathrm{kJ} \cdot \mathrm{mol}^{-1} \cdot \mathrm{K}^{-1}
\end{aligned}
$$

(3) Estimating heat capacity $C_{\mathrm{p}}$

Heat capacity of dry biomass and temperature showed a good linear relationship [28] and the proposed specific heat capacity of dry biomass as follows.

$$
c_{p}=1113.68+4.8567(T-273.15)=-212.928+4.8567 T \quad \mathrm{~J} \cdot \mathrm{kg}^{-1} \cdot \mathrm{K}^{-1}
$$

Then, Eq. (A.28) after unit conversion is written as.

$$
\begin{aligned}
C_{p} & =0.001 M c_{p}=0.1(-212.928+4.8567 T) \quad \mathrm{J} \cdot \mathrm{mol}^{-1} \cdot \mathrm{K}^{-1} \\
& =10^{-4}(-212.928+4.8567 T) \quad \mathrm{kJ} \cdot \mathrm{mol}^{-1} \cdot \mathrm{K}^{-1}
\end{aligned}
$$

\subsection{Simulation of anaerobic digestion}

In order to simulate the anaerobic digestion of biomass, first of all, the mass of input fermentation broth needs to be given. Hassan et al. [29] proposed a level of 5\% solids (TS\%) at mid-temperature anaerobic digestion when co-fermented with chicken manure and wheat straw. According to mass balance,

$$
5 \% \times m_{\text {broth }}=100 \times T S \%
$$

where $m_{\text {broth }}$ represents mass of fermentation broth, g. 100 in the right of Eq.(A.29) means the mass of biomass. 
Therefore, the mass of fermentation broth is as follows.

$m_{\text {broth }}=20 T S \quad \mathrm{~g}$

In this study, the PBMP model was used to simulate the anaerobic digestion process. The theoretical biochemical methane potential (TBMP) represented the maximum biomethane yield per volatile solid (VS). To get the TBMP, the organic carbon in biomass was assumed to be transferred into $\mathrm{CH}_{4}$ and $\mathrm{CO}_{2}$ (two main composition of biogas) completely during the anaerobic digestion process. Therefore, the reaction in the anaerobic digestion of biomass was written as follows [13]:

$$
\mathrm{C}_{x} \mathrm{H}_{y} \mathrm{O}_{z} \mathrm{~N}_{a}+\left(x-\frac{y}{4}-\frac{z}{2}+\frac{3 a}{4}\right) \mathrm{H}_{2} \mathrm{O} \rightarrow\left(\frac{x}{2}+\frac{y}{8}-\frac{z}{4}-\frac{3 a}{8}\right) \mathrm{CH}_{4}+\left(\frac{x}{2}-\frac{y}{8}+\frac{z}{4}+\frac{3 a}{8}\right) \mathrm{CO}_{2}+a \mathrm{NH}_{3}
$$

According to the definition of theTBMP, we can obtain the following equation,

$$
\operatorname{TBMP}\left(\frac{\mathrm{mLCH}_{4}}{\mathrm{~g} \mathrm{VS}}\right)=\frac{22.4 \times 1000 \times\left(\frac{x}{2}+\frac{y}{8}-\frac{z}{4}-\frac{3 a}{8}\right)}{12 x+y+16 z+14 a} \mathrm{~mL} \cdot \mathrm{g}^{-1}
$$

When considering the actual digestion conditions, biomass can't be degraded completely by microorganisms during the digestion process, so in order to get the PBMP, an important factor needs to be taken into account, namely the biodegradability (BD) [13]. In this study, a linear correlation (Eq. (A.32)) [22] was used to estimate the BD of biomass.

$$
\mathrm{BD}=(80.4-2.70 \text { Lignin }) \%
$$

Then the PBMP can be calculated from the TBMP and BD by Eq. (A.33):

$$
\begin{aligned}
\operatorname{PBMP}\left(\frac{\mathrm{mLCH}_{4}}{\mathrm{~g} \mathrm{VS}}\right) & =\mathrm{BD} \times \mathrm{TBMP} \\
& =(80.4-2.70 \text { Lignin }) \% \times \frac{22.4 \times 1000 \times\left(\frac{x}{2}+\frac{y}{8}-\frac{z}{4}-\frac{3 a}{8}\right)}{12 x+y+16 z+14 a} \\
& =(80.4-2.70 \text { Lignin }) \% \times \frac{22.4 \times 1000 \times\left(\frac{\mathrm{C}}{24}+\frac{\mathrm{H}}{8}-\frac{\mathrm{O}}{64}-\frac{3 \mathrm{~N}}{112}\right)}{\mathrm{C}+\mathrm{H}+\mathrm{O}+\mathrm{N}} \mathrm{mL} \cdot \mathrm{g}^{-1}
\end{aligned}
$$

Actually, comparing to the PBMP per VS, we are more concerned with the PBMP per biomass. According to the definition of VS and TS, Eq.(A.34) can be obtained.

$\mathrm{C}+\mathrm{H}+\mathrm{O}+\mathrm{N}=\frac{\mathrm{VS}}{\mathrm{TS}} \times 100$

Therefore, 


$$
\begin{aligned}
\operatorname{PBMP}\left(\frac{\mathrm{mLCH}_{4}}{\mathrm{~g} \mathrm{VS}}\right) & =(80.4-2.70 \text { Lignin }) \% \times \frac{22400 \times\left(\frac{\mathrm{C}}{24}+\frac{\mathrm{H}}{8}-\frac{\mathrm{O}}{64}-\frac{3 \mathrm{~N}}{112}\right)}{\frac{\mathrm{VS}}{\mathrm{TS}} \times 100} \\
& =(80.4-2.70 \text { Lignin }) \% \times \frac{22400 \times T S \%\left(\frac{\mathrm{C}}{24}+\frac{\mathrm{H}}{8}-\frac{\mathrm{O}}{64}-\frac{3 \mathrm{~N}}{112}\right)}{\mathrm{VS}} \mathrm{mL} \cdot \mathrm{g}^{-1}
\end{aligned}
$$

Then, PBMP per biomass can be calculated by Eq. (8):

$$
\begin{aligned}
\operatorname{PBMP}\left(\frac{\mathrm{mLCH}_{4}}{\mathrm{~g} \mathrm{wb}}\right) & =(80.4-2.70 \text { Lignin }) \% \times \frac{22400 \times T S \%\left(\frac{\mathrm{C}}{24}+\frac{\mathrm{H}}{8}-\frac{\mathrm{O}}{64}-\frac{3 \mathrm{~N}}{112}\right)}{100} \\
& =(80.4-2.70 \text { Lignin }) \% \times 224 T S \% \times\left(\frac{\mathrm{C}}{24}+\frac{\mathrm{H}}{8}-\frac{\mathrm{O}}{64}-\frac{3 \mathrm{~N}}{112}\right) \mathrm{mL} \cdot \mathrm{g}^{-1}
\end{aligned}
$$

(8)

The volume and mole of biogas can be obtained by Eq.(9) and Eq.(10) respectively for the mass of biomass is $100 \mathrm{~g}$.

$$
\begin{aligned}
V_{\mathrm{CH} 4} & =100 \times \operatorname{PBMP}\left(\frac{\mathrm{mLCH}_{4}}{\mathrm{~g} \mathrm{wb}}\right) \\
& =(80.4-2.70 \text { Lignin }) \% \times 22400 T S \% \times\left(\frac{\mathrm{C}}{24}+\frac{\mathrm{H}}{8}-\frac{\mathrm{O}}{64}-\frac{3 \mathrm{~N}}{112}\right) \mathrm{mL} \\
n_{\mathrm{CH} 4} & =V_{\mathrm{CH}_{4} / 22.4 \times 10^{3}} \\
& =(80.4-2.70 \text { Lignin }) \% \times T S \% \times\left(\frac{\mathrm{C}}{24}+\frac{\mathrm{H}}{8}-\frac{\mathrm{O}}{64}-\frac{3 \mathrm{~N}}{112}\right) \mathrm{mol}
\end{aligned}
$$

\section{Calculating exergy for process evalution}

The total exergy value of substance equals to the sum of all kinds of exergy values [30],

$$
E x=E x^{k i}+E x^{p o}+E x^{p h}+E x^{c h}
$$

where $E x^{k i}, E x^{p o}, E x^{p h}$ and $E x^{c h}$ denote the exergy flow rate of kinetic energy, potential energy, physical energy and chemical energy, respectively. Neglecting the kinetic exergy $\left(m V^{2} / 2\right)$ and potential exergy ( $m g Z$ ), the exergy flow rate of gas can be simplified as,

$$
E x=E x^{p h}+E x^{c h}
$$

Exergy of heat input is calculated by Eq. (A.38):

$$
E x_{\text {heat }}=\left(1-\frac{T_{0}}{T}\right) Q \quad \mathrm{~kJ}
$$

where $\left(1-\frac{T_{0}}{T}\right)$ means the Carnot efficiency, $Q$ is the energy of heat input, kJ.

2.1. Exergy of biomass $E x_{\mathrm{wb}, \text { total }}$

The exergy of biomass is equal to chemical exergy for its physical exergy is 0 [31]. The exergy of 
biomass is composed of the exergy of dry biomass and that of liquid water. In this study, the specific chemical exergy of dry biomass was calculated by Eq. (A.39) proposed by our previous study [19].

$$
e_{\mathrm{db}}=920.72\left(\frac{1}{3} \mathrm{C}+\mathrm{H}\right) \quad \mathrm{kJ}^{\mathrm{kg}} \mathrm{kg}^{-1}
$$

Eq. (A.40) can be obtained via unit conversion for the molecular weight of dry biomass (taken as $\left.100 \mathrm{~g} \cdot \mathrm{mol}^{-1}\right)$ :

$$
\begin{aligned}
E x_{\mathrm{db}} & =0.1 e_{\mathrm{db}} \\
& =0.1 \times 920.72\left(\frac{1}{3} \mathrm{C}+\mathrm{H}\right) \\
& =92.072\left(\frac{1}{3} \mathrm{C}+\mathrm{H}\right) \quad \mathrm{kJ}^{\prime} \mathrm{mol}^{-1}
\end{aligned}
$$

The molar exergy of liquid water is $0.95 \mathrm{~kJ}^{-\mathrm{mol}^{-1}}$, then, the total exergy of $100 \mathrm{~g}$ biomass was obtained.

$$
\begin{aligned}
E x_{\mathrm{wb}, \text { total }} & =n_{\mathrm{db}} E x_{\mathrm{db}}+n_{\mathrm{water}} E x_{\mathrm{H} 2 \mathrm{O}} \\
& =(T S / 100) E x_{\mathrm{db}}+((100-T S) / 18) E x_{\mathrm{H} 2 \mathrm{O}} \\
& =92.072\left(\frac{1}{3} \mathrm{C}+\mathrm{H}\right) \times T S \%+0.95 \times 5.556(1-T S \%) \\
& =92.072\left(\frac{1}{3} \mathrm{C}+\mathrm{H}\right) \times T S \%+5.278 \times(1-T S \%) \quad \mathrm{kJ}
\end{aligned}
$$

It has been verified that exergy can be predicted by Eq. (A.39) with the element contents in dry biomass in our previous study [19], so it is also reasonable and accurate that the exergy of biomass is calculated by Eq. (A.41) with element contents.

\subsection{Exergy input of drying process}

Drying process of biomass can be divided into two stages, heating biomass to $100^{\circ} \mathrm{C}$ and $100{ }^{\circ} \mathrm{C}$ water to vapor, their energy is $\int_{T_{0}}^{373.15} C_{p, \mathrm{H} 2 \mathrm{O}} \mathrm{d} T$ and $\Delta_{\text {vap }} H_{\mathrm{m}}\left(40.668 \mathrm{~kJ} \cdot \mathrm{mol}^{-1}\right)$, respectively.

$$
E x_{\text {heatl }}=\left(1-\frac{T_{0}}{T_{D r y}}\right)\left(\int_{T_{0}}^{373.15} C_{p, \mathrm{H} 2 \mathrm{O}} \mathrm{d} T+\Delta_{\text {vap }} H_{\mathrm{m}}\right) \mathrm{kJ} \cdot \mathrm{mol}^{-1}
$$

where $T_{D r y}$ is drying temperature $\left(100{ }^{\circ} \mathrm{C}\right.$ in this study), $T_{0}$ is ambient temperature $\left(25^{\circ} \mathrm{C}\right.$ in this study), $\left(1-\frac{T_{0}}{T_{D r y}}\right)$ means Carnot efficiency, $C_{p, \mathrm{H} 2 \mathrm{O}}$ represents the molar heat capacity of liquid water, $\mathrm{kJ} \cdot \mathrm{mol}^{-1} \cdot \mathrm{K}^{-1}$.

The exergy used to dry $100 \mathrm{~g}$ biomass in pyrolysis process is as follows:

$$
\begin{aligned}
E x_{\text {heat } 1 \text { total }}= & n_{\text {water }} E x_{\text {heat1 }} \\
& =n_{\text {water }}\left(1-\frac{T_{0}}{T_{D r y}}\right)\left(\int_{T_{0}}^{373.15} C_{p, \text { H2O }} \mathrm{d} T+40.668\right) \\
& =5.556(1-T S \%)\left(1-\frac{T_{0}}{T_{D r y}}\right)\left(\int_{T_{0}}^{373.15} C_{p, \text { H2O }} \mathrm{d} T+40.668\right) \mathrm{kJ}
\end{aligned}
$$


Exergy input of drying process of gasification process $E x_{\text {heat, total }}$ is equal to that of pyrolysis process $E x_{\text {heat } 1, \text { toal }}$.

\subsection{Exergy input of reactor}

2.3.1. Exergy input of pyrolysis reactor $E x_{\text {heat, total }}$

Input exergy to heat and maintain biomass in pyrolysis reactor was calculated by Eq. (A.44):

$$
E x_{\text {heat } 2}=\left(1-\frac{T_{0}}{T_{I}}\right) \int_{T_{0}}^{T_{I}} C_{p, \mathrm{db}} \mathrm{d} T \quad \mathrm{~kJ} \cdot \mathrm{mol}^{-1}
$$

where $C_{p, \mathrm{db}}$ is molar heat capacity of dry biomass (calculated by Eq.(7)), $\mathrm{kJ} \cdot \mathrm{mol}^{-1} \cdot \mathrm{K}^{-1} \cdot T_{I}$ represents the pyrolysis temperature in the reactor.

Then, the total input exergy of pyrolysis reactor can be calculated,

$$
\begin{aligned}
E x_{\text {heat2,total }} & =n \mathrm{db} E x_{\text {heat2 }} \\
& =T S \% \times\left(1-\frac{T_{0}}{T_{I}}\right) \int_{T 0}^{T_{I}} C_{p, \mathrm{db}} \mathrm{d} T \quad \mathrm{~kJ}
\end{aligned}
$$

\subsubsection{Exergy input of gasification reactor $E x_{\text {heat } 4 \text {,total }}$}

The heat input to the gasification process primarily brings biomass and oxygen to the gasification temperature $T_{I I}$. Calculation formula of input exergy of gasification process for heating biomass is same to that of pyrolysis process except the heat temperature.

$$
E x_{\text {heat } 4 \text {, db, total }}=T S \% \times\left(1-\frac{T_{0}}{T_{I I}}\right) \int_{T_{0}}^{T_{I I}} C_{p, \mathrm{db}} \mathrm{d} T \quad \mathrm{~kJ}
$$

Calculation formula of input exergy for heating oxygen is as follows: (the amount of oxygen added is determined by equivalence ratio (ER))

$$
E x_{\text {heat4, } \mathrm{O}_{2}}=\left(1-\frac{T_{0}}{T_{I I}}\right) \int_{T_{0}}^{T_{I I}} C_{p, \mathrm{O}_{2}} \mathrm{~d} T \mathrm{~kJ} \cdot \mathrm{mol}^{-1}
$$

The amount of oxygen added to $100 \mathrm{~g}$ of biomass gasification is set to $n_{\mathrm{O}_{2}}$, then the total exergy input required was calculated by Eq. (A.48):

$$
E x_{\text {heat } 4, \mathrm{O} 2 \text {, total }}=n \mathrm{O}_{2}\left(1-\frac{T_{0}}{T_{I I}}\right) \int_{T_{0}}^{T_{I I}} C_{p, \mathrm{O}_{2}} \mathrm{~d} T \quad \mathrm{~kJ}
$$

Therefore, the calculation formula of the total of exergy input is as follows:

$$
E x_{\text {heat } 4 \text {,total }}=E x_{\text {heat }, \text { O2, total }}+E x_{\text {heat }, \text { db, total }} \quad \mathrm{kJ}
$$

\subsubsection{Exergy input of anaerobic digestion $E x_{\text {heat5, total }}$}

The specific exergy required for heating the anaerobic digestion process is, 


$$
e_{\text {heats }}=\left(1-\frac{T_{0}}{T_{I I I}}\right) \int_{T 0}^{T_{I I}} c_{p, \text { broth }} \mathrm{d} T \quad \mathrm{~kJ} \cdot \mathrm{kg}^{-1}
$$

where $T_{I I I}$ is the temperature of anaerobic digestion, ${ }^{\circ} \mathrm{C} . \quad c_{p, b r o t h}$ is the specific heat capacity of fermentation broth (not the biomass), $\mathrm{kJ} \cdot \mathrm{kg}^{-1} \cdot \mathrm{K}^{-1}$. In this study, the specific heat capacity of the fermentation broth is assumed to be equal to that of water for the amount of water is dominant in the fermentation broth $(T S=5 \%)$.

Then, the calculation formula of the total exergy is as follows:

$$
\begin{aligned}
E x_{\text {heat5, total }} & =m_{\text {broth }} e_{\text {heat5 }} \\
& =20 T S \times\left(1-\frac{T_{0}}{T_{I I I}}\right) \int_{T_{0}}^{T_{I I}} 4.2 \mathrm{~d} T \quad \mathrm{~J} \\
& =0.02 T S \times\left(1-\frac{T_{0}}{T_{I I I}}\right) \times 4.2 \times\left(T_{I I I}-T_{0}\right) \quad \mathrm{kJ}
\end{aligned}
$$

\subsection{Exergy of gas [32]}

The molar physical exergy of gas is calculated by Eq. (A.52):

$$
E x^{p h}=\left(H-H_{0}\right)-T\left(S-S_{0}\right)
$$

where $H$ and $S$ are the molar enthalpy and entropy of gas under working condition, $H_{0}$ and $S_{0}$ are the molar enthalpy and entropy of gas at the standard reference state.

Difference of molar enthalpy $\left(H-H_{0}\right)$ and difference of molar entropy $\left(S-S_{0}\right)$ are denoted as:

$$
\begin{aligned}
& H-H_{0}=\int_{T_{0}}^{T} C_{p} \mathrm{~d} T \quad \mathrm{~kJ} \cdot \mathrm{mol}^{-1} \\
& S-S_{0}=\int_{T_{0}}^{T} \frac{C_{p}}{T} \mathrm{~d} T-R \ln \frac{p}{p_{0}} \mathrm{~kJ} \cdot \mathrm{mol}^{-1} \cdot \mathrm{K}^{-1}
\end{aligned}
$$

where, $R$ is the general gas constant, $8.314 \times 10^{-3} \mathrm{~kJ}^{-m_{0}}{ }^{-1} \mathrm{~K}^{-1} \cdot C_{p}$ is the molar heat capacity at constant pressure, $\mathrm{kJ}^{\mathrm{mol}}{ }^{-1} \mathrm{~K}^{-1} \cdot p$ is the pressure under working condition, $p_{0}=0.1 \mathrm{MPa}$ is the pressure at the standard reference state.

Finally, the calculation formula of molar physical exergy of gas for omitting the effect of pressure is as follows:

$$
E x^{p h}=\int_{T_{0}}^{T} C_{p} \mathrm{~d} T-T_{0} \int_{T_{0}}^{T} \frac{C_{p}}{T} \mathrm{~d} T \quad \mathrm{~kJ} \cdot \mathrm{mol}^{-1}
$$

The molar chemical exergy of gas is calculated by Eq.(A.56):

$$
E x^{c h}=\sum x_{i}\left(e_{i}^{c h}+R T_{0} \ln x_{i}\right) \quad \mathrm{kJ} \cdot \mathrm{mol}^{-1}
$$

where $x_{i}$ is the mole fraction of the $i$-th component in the gas. $e_{i}^{c h}$ is the molar chemical exergy of $i$-th component, $\mathrm{kJ} \cdot \mathrm{mol}^{-1}$. 


\subsubsection{Exergy of syngas $E x_{\text {syngas,total }}$}

Syngas is composed of $\mathrm{H}_{2}$ and $\mathrm{CO}$, therefore, the physical exergy of syngas can be calculated.

$$
E x_{\text {total }}^{p h}=n_{\mathrm{H} 2} E x^{p h}{ }_{\mathrm{H} 2}+n_{\mathrm{co}} E x^{p h} \mathrm{CO} \mathrm{kJ}
$$

where $E x^{p h} \mathrm{H}_{2}$ and $E x^{p h} \mathrm{CO}$ are the molar physical exergy of $\mathrm{CO}$ and $\mathrm{H}_{2}$, their values are calculated by Eq.(A.55).

According to Eq. (A.56), the calculation formula of molar chemical exergy of syngas is,

$$
E x^{c h}=x_{\mathrm{H} 2}\left(e_{\mathrm{H} 2}^{c h}+R T_{0} \ln x_{\mathrm{H} 2}\right)+x_{\mathrm{CO}}\left(e_{\mathrm{CO}}^{c h}+R T_{0} \ln x_{\mathrm{CO}}\right) \quad \mathrm{kJ} \cdot \mathrm{mol}^{-1}
$$

where

$$
\begin{aligned}
& x_{\mathrm{H} 2}=\frac{n_{\mathrm{H} 2}}{n_{\text {total }}}=\frac{n_{\mathrm{H} 2}}{n_{\mathrm{H} 2}+n_{\mathrm{CO}}} \\
& x_{\mathrm{CO}}=\frac{n_{\mathrm{CO}}}{n_{\text {total }}}=\frac{n_{\mathrm{CO}}}{n_{\mathrm{H} 2}+n_{\mathrm{CO}}}
\end{aligned}
$$

Then the chemical exergy of syngas is calculated by Eq. (A.61).

$$
\begin{aligned}
E x^{c h}{ }_{\text {total }} & =n_{\text {total }} E x^{c h} \\
& =n_{\mathrm{H} 2}\left(e_{\mathrm{H} 2}^{c h}+R T_{0} \ln x_{\mathrm{H} 2}\right)+n_{\mathrm{CO}}\left(e_{\mathrm{CO}}^{c h}+R T_{0} \ln x_{\mathrm{CO}}\right) \quad \mathrm{kJ}
\end{aligned}
$$

Finally, according to Eq. (A.37), the total exergy of syngas is calculated by Eq. (A.62).

$$
E x_{\text {syngas,total }}=E x_{\text {total }}^{p h}+E x_{\text {total }}^{c h} \quad \mathrm{~kJ}
$$

\subsubsection{Exergy of biogas $E x_{\text {biogas,total }}$}

The temperature of mesophilic anaerobic digestion is $37^{\circ} \mathrm{C}$, which is very close to the environment $\left(25^{\circ} \mathrm{C}, 1 \mathrm{~atm}\right)$. Therefore, the physical exergy of biogas is negligible in this study. For biogas product of anaerobic digestion of biomass, only $\mathrm{CH}_{4}$ is the target product, then the specific exergy of biogas can be calculated as follows:

$$
\begin{aligned}
& E x^{c h}=x_{\mathrm{CH} 4} e_{\mathrm{CH} 4}^{c h} \mathrm{~kJ} \cdot \mathrm{mol}^{-1} \\
& x_{\mathrm{CH} 4}=\frac{n_{\mathrm{CH} 4}}{n_{\text {total }}}=\frac{n_{\mathrm{CH} 4}}{n_{\mathrm{CH} 4}+n_{\mathrm{CO} 2}}
\end{aligned}
$$

A.ccording to Eq. (A.37), the total exergy of biogas can be calculated.

$$
E x_{\text {biogas,total }}=n_{\text {total }} E x^{c h}=n_{\mathrm{CH} 4} e_{\mathrm{CH} 4}^{c h} \quad \mathrm{~kJ}
$$




\section{Nomenclature}

BD biodegradability of biomass

$C_{p, \mathrm{H}_{2} \mathrm{O}} \quad$ molar heat capacity of liquid water, $\mathrm{kJ} \cdot \mathrm{mol}^{-1} \cdot \mathrm{K}^{-1}$

$C_{p, \mathrm{db}} \quad$ molar heat capacity of dry biomass, $\mathrm{kJ} \cdot \mathrm{mol}^{-1} \cdot \mathrm{K}^{-1}$

$C_{p, \mathrm{O}_{2}} \quad$ molar heat capacity of oxygen, $\mathrm{kJ} \cdot \mathrm{mol}^{-1} \cdot \mathrm{K}^{-1}$

$c_{p, \text { broth }} \quad$ specific heat capacity of fermentation broth, $\mathrm{kJ} \mathrm{kg}^{-1} \cdot \mathrm{K}^{-1}$

$E x_{\text {heatl }} \quad$ molar exergy input of drying process , $\mathrm{kJ}^{\mathrm{m}} \mathrm{mol}^{-1}$

$E x_{\text {heat 1,total }} \quad$ exergy input of drying process of $100 \mathrm{~g}$ biomass in pyrolysis process, $\mathrm{kJ}$

$E x_{\text {heat2 }} \quad$ molar exergy input of pyrolysis reactor, $\mathrm{kJ} \cdot \mathrm{mol}^{-1}$

$E x_{\text {heat2,total }} \quad$ exergy input of pyrolysis reactor for $100 \mathrm{~g}$ biomass, $\mathrm{kJ}$

$E x_{\text {heat3,total }}$ exergy input of drying process of $100 \mathrm{~g}$ biomass in gasification process, $\mathrm{kJ}$

$E x_{\text {heat } 4 \text {, db, total }}$ exergy input for heating dry biomass in gasification reactor for $100 \mathrm{~g}$ biomass, $\mathrm{kJ}$

$E x_{\text {heat } 4, \mathrm{O}_{2}} \quad$ molar exergy input for heating oxygen, $\mathrm{kJ} \cdot \mathrm{mol}^{-1}$

$E x_{\text {heat } 4, \mathrm{O}_{2} \text {, total }}$ exergy input for heating oxygen in gasification reactor for $100 \mathrm{~g}$ biomass, $\mathrm{kJ}$

$E x_{\text {heat } 4 \text {,total }}$ exergy input of gasification reactor for $100 \mathrm{~g}$ biomass, $\mathrm{kJ}$

$E x_{\text {heat5,total }}$ exergy input of anaerobic digestion for $100 \mathrm{~g}$ biomass, $\mathrm{kJ}$

$E x_{\text {biogas,total }} \quad$ total exergy of biogas, $\mathrm{kJ}$

$E x_{\text {syngas,total }} \quad$ total exergy of syngas, $\mathrm{kJ}$

$E x_{\text {wb,total }} \quad$ total exergy of $100 \mathrm{~g}$ biomass, $\mathrm{kJ}$ 
$E x_{\mathrm{db}} \quad$ molar chemical exergy of dry biomass, $\mathrm{kJ} \mathrm{mol}^{-1}$

$e_{\mathrm{db}} \quad$ specific chemical exergy of dry biomass, $\mathrm{kJ} \cdot \mathrm{kg}^{-1}$

$e_{\text {heat5 }} \quad$ specific chemical exergy required for heating the anaerobic digestion of biomass, $\mathrm{kJ}^{\mathrm{k}} \mathrm{kg}^{-1}$

$G_{T, p}^{t} \quad$ total Gibbs energy of the system, $\mathrm{kJ} \cdot \mathrm{mol}^{-1}$

$H H V \quad$ higher heat value, $\mathrm{kJ} \cdot \mathrm{kg}^{-1}$

$M \quad$ molecular weight of dry biomass, $\mathrm{g} \cdot \mathrm{mol}^{-1}$

$m_{\mathrm{db}} \quad$ mass of dry biomass, $\mathrm{g}$

$m_{\mathrm{wb}} \quad$ mass of biomass, $\mathrm{g}$

$m_{\text {water }} \quad$ mass of water, $\mathrm{g}$

$m_{\text {broth }} \quad$ mass of fermentation broth, $\mathrm{g}$

$n_{\mathrm{db}} \quad$ mole of dry biomass, $\mathrm{g}$

$n_{i} \quad$ equilibrium composition is referred to each species, mol

$n_{\text {water }} \quad$ mole of water, mol

$n_{\mathrm{CH} 4} \quad$ mole of biogas, mol

PBMP practical biochemical methane potential

$Q \quad$ energy of heat input, kJ

$S_{\mathrm{m}}^{o} \quad$ standard molar entropy, $\mathrm{kJ} \cdot \mathrm{mol}^{-1} \cdot \mathrm{K}^{-1}$

R universal gas constant, $8.314 \times 10^{-3} \mathrm{~kJ} \cdot \mathrm{mol}^{-1} \cdot \mathrm{K}^{-1}$

TS total solid

$T_{\text {Dry }} \quad$ drying temperature, ${ }^{\circ} \mathrm{C}$

$T_{0} \quad$ ambient temperature, ${ }^{\circ} \mathrm{C}$

$T_{I} \quad$ pyrolysis temperature in the reactor, ${ }^{\circ} \mathrm{C}$

$T_{I I} \quad$ gasification temperature in the reactor, ${ }^{\circ} \mathrm{C}$

$T_{I I I} \quad$ temperature of anaerobic digestion reactor, ${ }^{\circ} \mathrm{C}$

VS volatile solid

$V_{\mathrm{CH} 4} \quad$ volume of biogas, $\mathrm{mL}$

$\Delta_{\mathrm{f}} H_{\mathrm{m}}^{o} \quad$ standard molar enthalpy of formation, $\mathrm{kJ} \cdot \mathrm{mol}^{-1}$

$\Delta_{\text {vap }} H_{\mathrm{m}} \quad$ molar enthalpy of vaporization, $\mathrm{kJ} \cdot \mathrm{mol}^{-1}$ 
Greek symbols

$\eta_{I} \quad$ functional exergy efficiency of pyrolysis process

$\eta_{I I} \quad$ functional exergy efficiency of oxygen gasification process

$\eta_{I I I} \quad$ functional exergy efficiency of anaerobic digestion process

\section{References}

[1] Sikarwar VS, Zhao M, Clough P, Yao J, Zhong X, Memon MZ, et al. An overview of advances in biomass gasification. Energy Environ Sci. 2016;9(10):2939-77.

[2] Kirubakaran V, Sivaramakrishnan V, Nalini R, Sekar T, Premalatha M, Subramanian P. A review on gasification of biomass. Renew Sust Energy Rev. 2009;13(1):179-86.

[3] Cox PM, Betts RA, Jones CD, Spall SA, Totterdell IJ. Acceleration of global warming due to carbon-cycle feedbacks in a coupled climate model. Nature. 2000;408(6809):184-7.

[4] Tsao G, Ouyang P, Chen J. Biotechnology in China II: chemicals, energy and environment: Springer, 2010.

[5] Demirbas A. Biomass resource facilities and biomass conversion processing for fuels and chemicals. Energy Convers Manage. 2001;42(11):1357-78.

[6] Chaurasia A. Modeling, simulation and optimization of downdraft gasifier: Studies on chemical kinetics and operating conditions on the performance of the biomass gasification process. Energy. 2016;116:1065-76.

[7] Holubar P, Zani L, Hagar M, Fröschl W, Radak Z, Braun R. Modelling of anaerobic digestion using self-organizing maps and artificial neural networks. Water Sci Technol. 2000;41(12):149-56.

[8] Aydin ES, Yucel O, Sadikoglu H. Development of a semi-empirical equilibrium model for downdraft gasification systems. Energy. 2017;130:86-98.

[9] Wang K, Yu Q, Qin Q, Hou L, Duan W. Thermodynamic analysis of syngas generation from biomass using chemical looping gasification method. Int J Hydrogen Energy. 2016;41(24):10346-53.

[10] Donoso-Bravo A, Mailier J, Martin C, Rodríguez J, Aceves-Lara CA, Wouwer AV. Model selection, identification and validation in anaerobic digestion: a review. Water Res. 2011;45(17):5347-64.

[11] Batstone D, Keller J, Angelidaki I, Kalyuzhnyi S, Pavlostathis S, Rozzi A, et al. IWA Task Group on Modelling of Anaerobic Digestion Processes, Anaerobic Digestion Model No. 1 (ADM1): IWA Publishing, London, 2002.

[12] Haider M, Pakshirajan K, Singh A, Chaudhry S. Artificial neural network-genetic algorithm approach to optimize media constituents for enhancing lipase production by a soil microorganism. Appl Biochem Biotech. 2008;144(3):225-35.

[13] Liu C, Wang J, Ji X, Qian H, Huang L, Lu X. The biomethane producing potential in China: A theoretical and practical estimation. Chinese J Chem Eng. 2016;24(7):920-8.

[14] DiPippo R. Second law assessment of binary plants generating power from low-temperature geothermal fluids. Geothermics. 2004;33(5):565-86.

[15] Wang X, Lv W, Guo L, Zhai M, Dong P, Qi G. Energy and exergy analysis of rice husk high-temperature pyrolysis. Int J Hydrogen Energy. 2016;41(46):21121-30.

[16] Peters JF, Petrakopoulou F, Dufour J. Exergy analysis of synthetic biofuel production via fast 
pyrolysis and hydroupgrading. Energy. 2015;79:325-36.

[17] Havukainen J, Uusitalo V, Niskanen A, Kapustina V, Horttanainen M. Evaluation of methods for estimating energy performance of biogas production. Renew Energy. 2014;66:232-40.

[18] Qian H, Guo X, Fan S, Hagos K, Lu X, Liu C, et al. A simple prediction model for higher heat value of biomass. J Chem Eng Data. 2016;61(12):4039-45.

[19] Qian H, Zhu W, Fan S, Liu C, Lu X, Wang Z, et al. Prediction models for chemical exergy of biomass on dry basis from ultimate analysis using available electron concepts. Energy. 2017;131:251-8.

[20] Lwin Y. Chemical equilibrium by Gibbs energy minimization on spreadsheets. Int J Eng Educ. 2000;16(4):335-9.

[21] Shabbar S, Janajreh I. Thermodynamic equilibrium analysis of coal gasification using Gibbs energy minimization method. Energy Convers Manage. 2013;65(3):755-63.

[22] Li Y, Zhang R, Liu G, Chen C, He Y, Liu X. Comparison of methane production potential, biodegradability, and kinetics of different organic substrates. Bioresour Technol. 2013;149(7):565-9.

[23] Yang H, Yan R, Chen H, Lee DH, Zheng C. Characteristics of hemicellulose, cellulose and lignin pyrolysis. Fuel. 2007;86(12-13):1781-8.

[24] Bhutto AW, Qureshi K, Harijan K, Abro R, Abbas T, Bazmi AA, et al. Insight into progress in pre-treatment of lignocellulosic biomass. Energy. 2017;122:724-45.

[25] Li X, Grace J, Watkinson A, Lim C, Ergüdenler A. Equilibrium modeling of gasification: a free energy minimization approach and its application to a circulating fluidized bed coal gasifier. Fuel. 2001;80(2):195-207.

[26] Barin I, Platzki G. Thermochemical data of pure substances: Wiley Online Library, 1989.

[27] Song G, Shen L, Xiao J. Estimating specific chemical exergy of biomass from basic analysis data. Ind Eng Chem Res. 2011;50(16):9758-66.

[28] Rath J, Wolfinger M, Steiner G, Krammer G, Barontini F, Cozzani V. Heat of wood pyrolysis. Fuel. 2003;82(1):81-91.

[29] Hassan M, Ding W, Shi Z, Zhao S. Methane enhancement through co-digestion of chicken manure and thermo-oxidative cleaved wheat straw with waste activated sludge: $\mathrm{AC} / \mathrm{N}$ optimization case. Bioresour Technol. 2016;211(2):534-41.

[30] Hepbasli A. A key review on exergetic analysis and assessment of renewable energy resources for a sustainable future. Renew Sust Energy Rev. 2008;12(3):593-661.

[31] Saidur R, BoroumandJazi G, Mekhilef S, Mohammed H. A review on exergy analysis of biomass based fuels. Renew Sust Energy Rev. 2012;16(2):1217-22.

[32] Li Q, Lin Y. Exergy analysis of the LFC process. Energy Convers Manage. 2016;108:348-54. 
-Functional exergy efficiency is extended as unified protocol in biomass utilization

-Thermodynamic data of biomasses are predicted by high accurate models

- Thermochemical and biochemical conversion are simulated via different methods

-Utilization pathways of biomasses are compared based on functional exergy efficiency 